\title{
Restricting HIV-1 pathways for escape using rationally designed anti-HIV-1 antibodies
}

\author{
Ron Diskin, ${ }^{1}$ Florian Klein, ${ }^{2}$ Joshua A. Horwitz, ${ }^{2}$ Ariel Halper-Stromberg, ${ }^{2}$ \\ D. Noah Sather, ${ }^{3}$ Paola M. Marcovecchio, ${ }^{1}$ Terri Lee, ${ }^{1}$ Anthony P. West Jr., ${ }^{1}$ \\ Han Gao, ${ }^{1}$ Michael S. Seaman, ${ }^{4}$ Leonidas Stamatatos,,${ }^{3,5}$ \\ Michel C. Nussenzweig, ${ }^{2,6}$ and Pamela J. Bjorkman ${ }^{1,6}$
}

'Division of Biology, California Institute of Technology, Pasadena, CA 91125

${ }^{2}$ Laboratory of Molecular Immunology, The Rockefeller University, New York, NY 10065

${ }^{3}$ Seattle Biomedical Research Institute, Seattle, WA 98109

${ }^{4}$ Beth Israel Deaconess Medical Center, Boston, MA 02215

${ }^{5}$ Department of Global Health, University of Washington, Seattle, WA 98109

${ }^{6}$ Howard Hughes Medical Institute, Chevy Chase, MD 20815

Recently identified broadly neutralizing antibodies (bNAbs) that potently neutralize most HIV-1 strains are key to potential antibody-based therapeutic approaches to combat HIV/AIDS in the absence of an effective vaccine. Increasing bNAb potencies and resistance to common routes of HIV-1 escape through mutation would facilitate their use as therapeutics. We previously used structure-based design to create the bNAb NIH45-46 ${ }^{\mathrm{G}} 4 \mathrm{~W}$, which exhibits superior potency and/or breadth compared with other bNAbs. We report new, more effective NIH45$46^{\mathrm{G5} 4 \mathrm{~W}}$ variants designed using analyses of the NIH45-46-gp120 complex structure and sequences of NIH45-46 ${ }^{654 \mathrm{~W}}$-resistant HIV-1 strains. One variant, 45-46m2, neutralizes $96 \%$ of HIV-1 strains in a cross-clade panel and viruses isolated from an HIV-infected individual that are resistant to all other known bNAbs, making it the single most broad and potent antiHIV-1 antibody to date. A description of its mechanism is presented based on a $45-46 \mathrm{~m} 2-$ gp120 crystal structure. A second variant, $45-46 \mathrm{m7}$, designed to thwart HIV-1 resistance to NIH45-46 ${ }^{654 \mathrm{~W}}$ arising from mutations in a gp 120 consensus sequence, targets a common route of HIV-1 escape. In combination, $45-46 \mathrm{~m} 2$ and $45-46 \mathrm{~m} 7$ reduce the possible routes for the evolution of fit viral escape mutants in $\mathrm{HIV}-1_{\mathrm{YU}-2}$-infected humanized mice, with viremic control exhibited when a third antibody, 10-1074, was added to the combination.

CORRESPONDENCE

Ron Diskin:

ron.diskin@weizmann.ac.il

Abbreviations used: bNAb, broadly neutralizing antibody; CD4bs, CD4 binding site; HC, heavy chain; LC, light chain; SPR, surface plasmon resonance.
The HIV/AIDS pandemic has claimed the lives of over 30 million people. Although antiretroviral drugs can control the progression of AIDS (Louie et al., 2003; Hofman and Nelson, 2006), they are not in general use in the developing world. As a completely protective vaccine against HIV-1 has not yet been found, prevention and treatment options involving delivery of broadly neutralizing antibodies (bNAbs) identified in a minority of HIV-infected individuals are being considered (Johnson et al., 2009; Balazs et al., 2012). bNAbs that target conserved epitopes on the HIV-1 envelope spike can prevent infection in animal models (Baba et al., 2000; Mascola et al., 2000; Hessell et al., 2009; Johnson et al., 2009;

F. Klein, J.A. Horwitz, A. Halper-Stromberg, and D. Noah Sather contributed equally to this paper.

R. Diskin's present address is Dept. of Structural Biology, Weizmann Institute of Science, Rehovot 76100, Israel.
Balazs et al., 2012), delay rebound of HIV-1 after cessation of antiretroviral drugs (Trkola et al., 2005; Mehandru et al., 2007), and treat an ongoing infection (Klein et al., 2012).

NIH45-46, isolated in a screen that yielded $>500$ HIV-1 antibodies using single cell cloning techniques (Scheid et al., 2009, 2011), is a more potent clonal variant of VRC01, a bNAb directed against the CD4 binding site (CD4bs) of gp120 (Wu et al., 2010; Zhou et al., 2010). Enhancing the efficacy of bNAbs, and in particular, designing bNAbs that retain potency against escape mutants selected during exposure to bNAbs, would facilitate their use as therapeutics. We previously used structure-based design to create

2013 Diskin et at. This article is distributed under the terms of an AttributionNoncommercial-Share Alike-No Mirror Sites license for the first six months after the publication date (see http://www.rupress.org/terms). After six months it is available under a Creative Commons License (Attribution-Noncommercial-Share Alike 3.0 Unported license, as described at http://creativecommons.org/licenses/ by-nc-sa/3.0/) 


\begin{tabular}{|c|c|c|c|c|}
\hline Mutant & \multicolumn{2}{|c|}{ Heavy chain } & \multicolumn{2}{c|}{ Light chain } \\
\cline { 2 - 6 } $45-46 \mathrm{~m} 2$ & G54W & & S28Y & \\
\hline $45-46 \mathrm{~m} 4$ & G54W & & S28Y & Y89N \\
\hline $45-46 \mathrm{~m} 5$ & G54W & & S28Y & Y89S \\
\hline $45-46 \mathrm{~m} 6$ & G54W & & S28Y & Y89T \\
\hline $45-46 \mathrm{~m} 7$ & G54W & W47V & S28Y & \\
\hline $45-46 \mathrm{~m} 8$ & G54W & W47A & S28Y & \\
\hline $45-46 \mathrm{~m} 9$ & G54W & W47L & S28Y & \\
\hline $45-46 \mathrm{~m} 16$ & G54W & W102H & S28Y & \\
\hline $45-46 \mathrm{~m} 17$ & G54W & W102N & S28Y & \\
\hline $45-46 \mathrm{~m} 18$ & G54W & W102S & S28Y & \\
\hline $45-46 \mathrm{~m} 20$ & G54W & W102F & S28Y & \\
\hline $45-46 \mathrm{~m} 21$ & G54W & W102L & S28Y & \\
\hline $45-46 \mathrm{~m} 22$ & G54W & W102T & S28Y & \\
\hline
\end{tabular}

\begin{tabular}{|l|c|c|c|c|}
\hline Mutant & \multicolumn{2}{|c|}{ Heavy chain } & \multicolumn{2}{c|}{ Light chain } \\
\hline $45-46 \mathrm{~m} 23$ & G54W & W102C & S28Y & \\
\hline $45-46 \mathrm{~m} 24$ & G54W & W47F & S28Y & \\
\hline $45-46 \mathrm{~m} 25$ & G54W & W47I & S28Y & \\
\hline $45-46 \mathrm{~m} 26$ & G54W & W47H & S28Y & \\
\hline $45-46 \mathrm{~m} 28$ & G54W & W47T & S28Y & \\
\hline $45-46 \mathrm{~m} 29$ & G54W & W102A & S28Y & \\
\hline $45-46 \mathrm{~m} 30$ & G54W & Y100N & S28Y & \\
\hline $45-46 \mathrm{~m} 31$ & G54W & Y100S & S28Y & \\
\hline $45-46 \mathrm{~m} 32$ & G54W & Y100K & S28Y & \\
\hline $45-46 \mathrm{~m} 34$ & G54W & & S28Y & Y89A \\
\hline $45-46 \mathrm{~m} 35$ & G54W & & S28Y & Y89G \\
\hline $45-46 \mathrm{~m} 36$ & G54W & & S28Y & Y89D \\
\hline
\end{tabular}

$B^{100}$

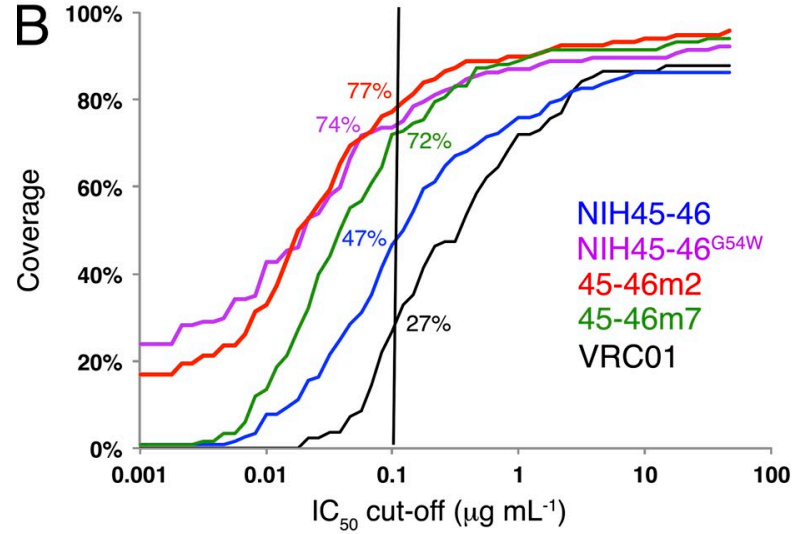

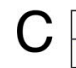

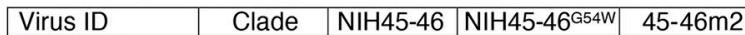

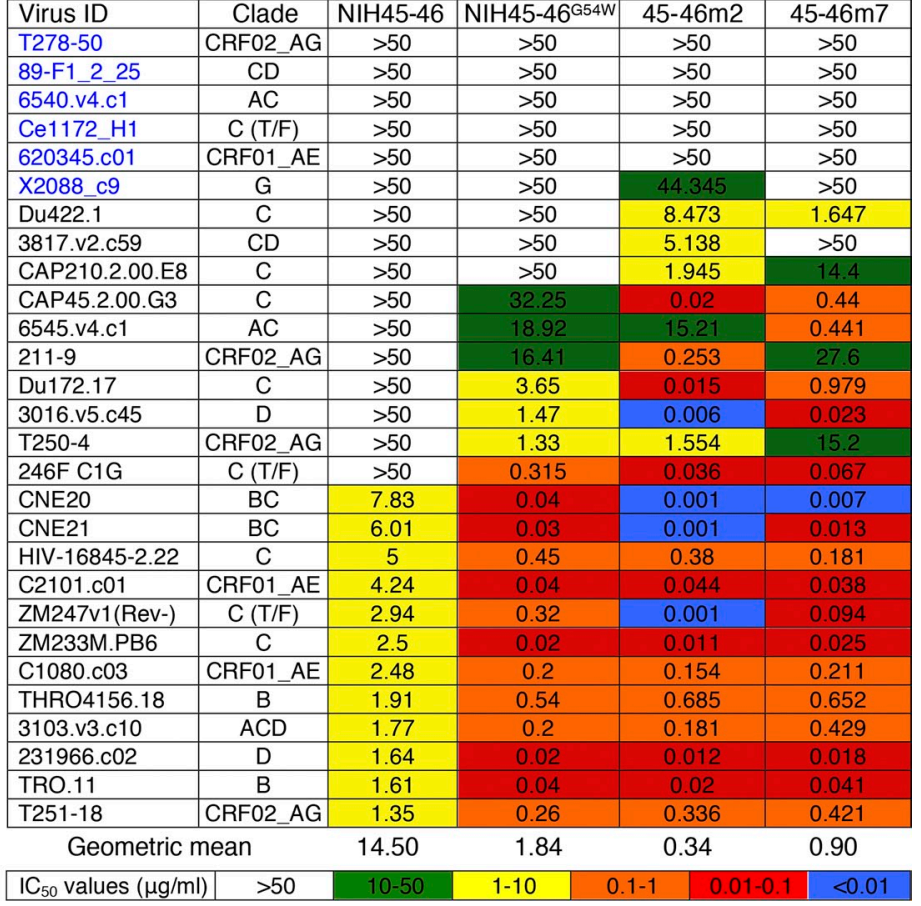

NIH45-46 ${ }^{\mathrm{G} 54 \mathrm{~W}}$, a single amino acid change from NIH45-46, which was the single most potent and broadly neutralizing antiHIV-1 antibody described to date (Diskin et al., 2011; Sather et al., 2012; Nakamura et al., 2013). It belongs to the PVL (potentVRC01-like) family of antibodies that target the CD4bs on the HIV-1 trimeric spike complex (West et al., 2012). The G54W substitution allows NIH45-46 $6^{\mathrm{G} 54 \mathrm{~W}}$ to use a conserved hydrophobic pocket on the surface of gp120, the Phe43 pocket,
Figure 1. Comparison of neutralization potencies of $45-46 \mathrm{~m}$ bNAb mutants. (A) Summary of $45-46 \mathrm{~m}$ mutants. (B) Coverage curves showing the cumulative frequency of $I_{50}$ values up to the concentration shown on the $x$ axis (plot of the percent of viral strains [y axis] from a panel of 118 strains that were neutralized at a given $I C_{50}$ cutoff $[x$ axis] $]$. A vertical line at $0.1 \mu \mathrm{g} / \mathrm{ml}$ designates a theoretical desired potency for a therapeutic reagent. (C) Table showing $\mathrm{IC}_{50}$ values $(\mu \mathrm{g} / \mathrm{ml})$ for $\mathrm{NIH} 45-$ 46, NIH45-46 G54W, 45-46m2, and 45-46m7 against 28 strains that are resistant to or poorly neutralized by NIH45-46. Strains marked in blue have an altered N/DNGG motif. $I \mathrm{C}_{50} \mathrm{~S}$ were derived from curves generated from data points obtained in duplicate or triplicate. which normally accommodates Phe $43_{\mathrm{CD} 4}$ of CD4 (Kwong et al., 1998), thereby enhancing both binding and neutralization (Diskin et al., 2011). Because HIV-1 infection usually emerges from a single viral strain (Keele et al., 2008), the ability of NIH45-46 $6^{\mathrm{G} 54 \mathrm{~W}}$ to neutralize transmitted founder strains and its high potency (Diskin et al., 2011) makes it a promising candidate for preventing infection via passive delivery (Baba et al., 2000; Mascola et al., 2000; Trkola et al., 2008; Hessell 



\begin{tabular}{|c|c|c|c|c|}
\hline Virus ID & VRC01 & $\mathrm{NIH} 45-46^{\mathrm{G} 54 \mathrm{~W}}$ & $45-46 \mathrm{~m} 2$ & $45-46 \mathrm{~m} 7$ \\
\hline VC10042.y19.72 & $>50$ & 5.8 & 0.66 & 2.32 \\
\hline VC10042.y19.101 & $>50$ & 7.9 & $<0.39$ & 1.06 \\
\hline VC10042.y19.113 & $>50$ & 7.4 & $<0.39$ & 0.64 \\
\hline VC10042.y19.205 & $>50$ & 6.9 & 0.46 & 0.69 \\
\hline VC10042.y22.01 & $>50$ & 4.65 & 1.22 & 1.13 \\
\hline VC10042.y22.02 & $>50$ & $>50$ & 2.2 & 12.36 \\
\hline VC10042.y22.03 & $>50$ & 2.67 & 1.21 & 1.11 \\
\hline VC10042.y22.04 & $>50$ & $>50$ & 3.37 & 14.45 \\
\hline VC10042.y22.05 & $>50$ & $>50$ & 2.21 & 8.83 \\
\hline VC10042.y22.06 & $>50$ & 12.7 & 0.47 & 0.61 \\
\hline VC10042.y22.07 & $>50$ & $>50$ & 2.74 & 10.54 \\
\hline VC10042.y22.08 & 0.018 & 9.73 & $<0.39$ & $<0.39$ \\
\hline $\mathrm{I}_{50}$ values $(\mu \mathrm{g} / \mathrm{ml})$ & $>50$ & $0-50$ & $0.1-1$ & $0.01-0.1$ \\
\hline
\end{tabular}

Figure 2. Neutralization of highly resistant viral clones from patient VC10042. (A) Neutralization curves for NIH45-46 G54W , 45-46m2, and 45-46m7 against 10 viral clones from patient VC10042 that were isolated 19 yr (first three panels) or 22 yr (remaining panels) after infection. (B) Scatter plot comparing $\mathrm{IC}_{50}$ values $(\mu \mathrm{g} / \mathrm{ml})$ for VRC01, NIH45-46 ${ }^{654 \mathrm{~W}}, 45-46 \mathrm{~m} 2$, and 45-46m7 against viral clones from patient VC10042. Despite their breadth, 45-46m2 and 45-46m7 did not neutralize SIV strains (SIVmac251 and SIVsmE660; not depicted). (C) IC 50 values ( $\mu \mathrm{g} / \mathrm{ml}$ ) for NIH45-46 ${ }^{654 \mathrm{~W}}$, 45-46m2, and 45-46m7 against viral clones from patient VC10042. The reported $I C_{50}$ values represent the mean of two independent experiments, each with two replicates. Significance of statistical differences: * (VRCO1 and 45-46m2), P<0.0001; ${ }^{* *}(\mathrm{NIH} 45-46$ G54W and $45-46 \mathrm{~m} 2), \mathrm{P}=0.0033 ;{ }^{* * *}(45-46 \mathrm{~m} 2$ and $45-46 \mathrm{~m} 7), P=0.0274$. Error bars represent standard deviation from the mean.

et al., 2009; Johnson et al., 2009; Balazs et al., 2012) or topical microbicide (Veazey et al., 2003; Denton et al., 2008) approaches. However, a small group of HIV-1 clones are naturally resistant to neutralization by NIH45-46 ${ }^{\mathrm{G} 54 \mathrm{~W}}$ (Diskin et al., 2011) and escape mutants emerge during exposure to NIH45-46 ${ }^{\mathrm{G} 54 \mathrm{~W}}$ (Klein et al., 2012). Here, we illustrate a mechanism by which the breadth of NIH45-46 $6^{\mathrm{G} 54 \mathrm{~W}}$ can be increased via extending contacts with gp120 and substitutions to render it less sensitive to likely escape mutants within a consensus signature escape motif on gp120.

\section{RESULTS}

\section{Increasing the potency of NIH45-46 ${ }^{\mathrm{G} 54 \mathrm{~W}}$}

We previously postulated that neutralization of an NIH45-46resistant virus by a chimera of the NIH45-46 heavy chain (HC) paired with the VRC01 light chain (LC) was achieved via additional contacts that Tyr $28_{\mathrm{VRC} 01(\mathrm{LC})}$, but not Ser28 $8_{\mathrm{NIH} 45-46(\mathrm{LC})}$, makes with an $N$-linked glycan attached to Asn276 $6_{\text {gp } 120}$ (Diskin et al., 2011) that is predicted to be present in $94.7 \%$ of $4279 \mathrm{Env}$ sequences in the Los Alamos HIV Sequence Database (www. hiv.lanl.gov/). In an effort to increase the breadth of NIH45$46^{\mathrm{G} 54 \mathrm{~W}}$, we introduced an S28Y substitution into the NIH45-46

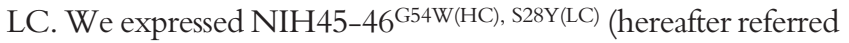
to as $45-46 \mathrm{~m} 2$; Fig. $1 \mathrm{~A}$ ) and evaluated it using in vitro neutralization assays against a cross-clade panel of 118 primary HIV-1 isolates including transmitted founder viruses (Tables S1 and S2). Against this panel, $45-46 \mathrm{~m} 2$ was as potent as $\mathrm{NIH} 45-46^{\mathrm{G} 54 \mathrm{~W}}$ (geometric mean $\mathrm{IC}_{50}$ values of 0.028 and $0.030 \mu \mathrm{g} / \mathrm{ml}$ for $45-46 \mathrm{~m} 2$ and NIH45-46 ${ }^{\mathrm{G} 54 \mathrm{~W}}$, respectively) but exhibited increased breadth (Fig. 1 B), neutralizing up to $96 \%$ of strains. Of 

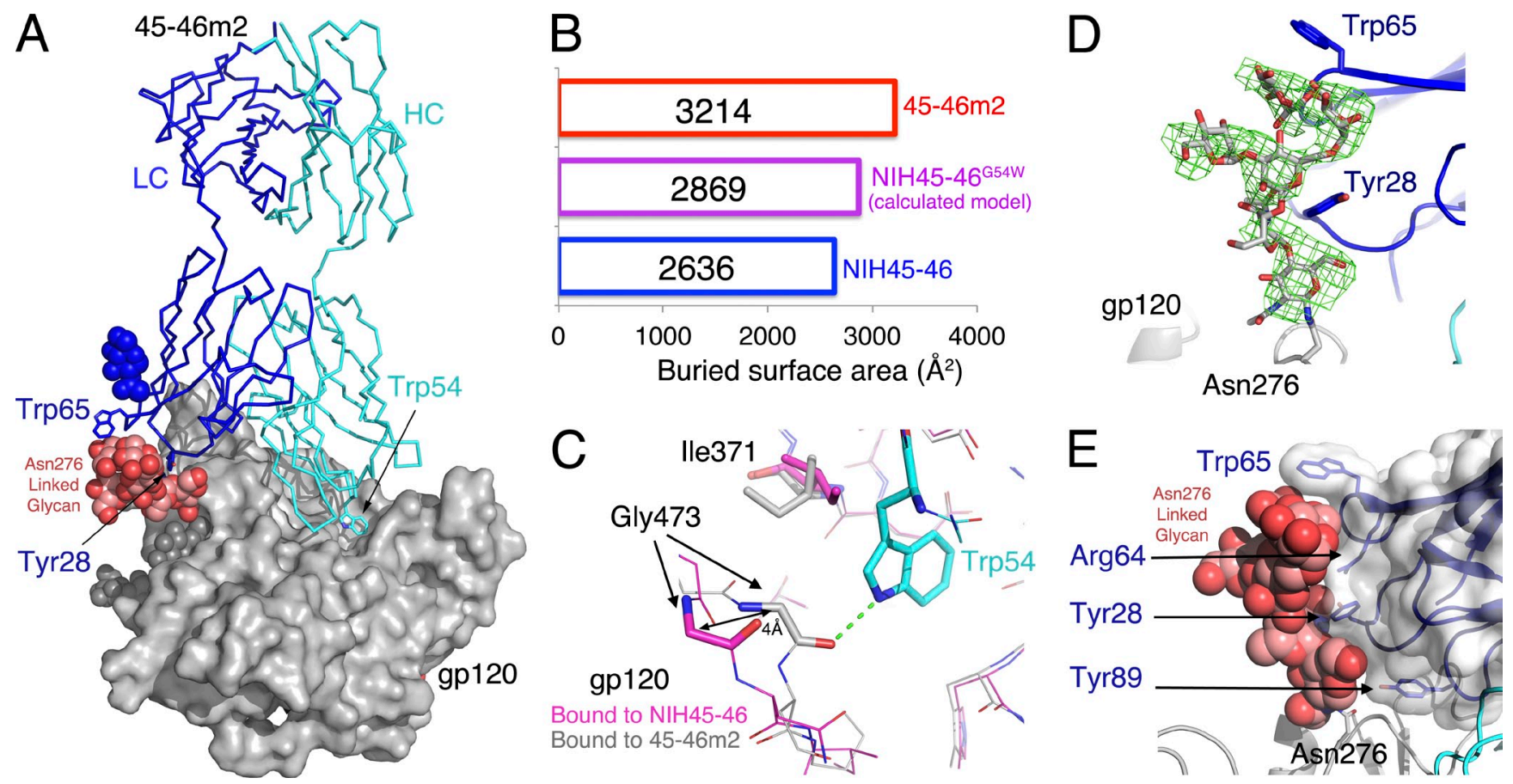

Figure 3. 45-46m2-gp120 complex structure. (A) 45-46m2/gp120 structure with gp120 as a gray surface and 45-46m2 Fab in cyan (HC) and blue (LC) $\mathrm{C} \alpha$ traces. Ordered $\mathrm{N}$-glycans are shown in van der Waals representation, with the Asn276 gp $120^{-}$-linked $\mathrm{N}$-glycan highlighted in shades of red. The locations of Tyr28 $8_{45-46 \mathrm{~m} 2(\mathrm{LC})}$ and $\operatorname{Trp}_{54} 4_{45-46 \mathrm{~m} 2(\mathrm{HC})}$ are indicated by arrows. (B) Buried surface areas between $\mathrm{gp} 120$ and the indicated antibodies. The buried surface area for NIH45-46 ${ }^{554 \mathrm{~W}}$ was calculated by adding the contribution of Trp54 (derived from the structure of 45-46m2/gp120) to the buried surface area calculated from the NIH45-46/gp120 structure. (C) Close-up comparison of the interactions of Trp54 $45-46 \mathrm{~m} 2$ (cyan side chain) and Gly54 $4_{\mathrm{NIH45}-46}$ (magenta) with gp120 in the structures of 45-46m2/gp120 (gray) and NIH45-46/gp120 (magenta). A hydrogen bond (green dashed line) between the nitrogen atom of the $\operatorname{Trp}_{45} 4_{45-46 m 2}$ indole ring and the main chain carbonyl oxygen of Gly473 ${ }_{\text {gp } 120}$ creates a $4 \AA$ shift (black arrow; $C \alpha-C \alpha$ distance) of the gp 120 main chain toward Trp54 $45-46 \mathrm{~m} 2$, and Ile $371_{\text {gp } 120}$ adopts a different rotamer to accommodate Trp54 $45-46 \mathrm{~m} 2$. (D) Electron density (green mesh; $\left.\sigma=2\right)$ for an N-linked glycan attached to Asn276 $g_{g p 120}$. A portion from the final model of the 45-46m2-gp120 complex is superimposed on an $F_{0}-F_{c}$ electron density map calculated using the initial model before adding the glycan and after several rounds of simulated annealing refinement. (E) Close-up of the Asn276 ${ }_{\text {gp } 120}$-attached glycan and its interactions with the $45-46 \mathrm{~m} 2 \mathrm{LC}$ (semitransparent surface). Side chains of Tyr28 ${ }_{45-46 \mathrm{~m} 2}, \operatorname{Trp}_{65}{ }_{45-46 \mathrm{~m} 2}$, Arg $4_{45-46 \mathrm{~m} 2}$, and Tyr89 ${ }_{45-46 \mathrm{~m} 2}$ are shown as sticks.

28 strains that were either poorly neutralized $\left(\mathrm{IC}_{50} \geq 1.0 \mu \mathrm{g} / \mathrm{ml}\right)$ or NIH45-46 resistant $\left(\mathrm{IC}_{50}>50 \mu \mathrm{g} / \mathrm{ml}\right), 45-46 \mathrm{~m} 2$ had a geometric mean $\mathrm{IC}_{50}$ of $0.35 \mu \mathrm{g} / \mathrm{ml}$ compared with geometric means of $1.84 \mu \mathrm{g} / \mathrm{ml}\left(\mathrm{NIH} 45-46^{\mathrm{G} 54 \mathrm{~W}}\right)$ and $14.51 \mu \mathrm{g} / \mathrm{ml}$ (NIH45-46; calculated with $\mathrm{IC}_{50} \mathrm{~s}>50 \mu \mathrm{g} / \mathrm{ml}$ input as $50 \mu \mathrm{g} / \mathrm{ml}$; Fig. 1 C).

We next compared the neutralizing activity of NIH45$46^{\mathrm{G} 54 \mathrm{~W}}$ and $45-46 \mathrm{~m} 2$ using viruses from an elite neutralizer, patient VC10042, who developed unusually broad and potent cross-neutralizing antibody responses but whose circulating viruses evolved to escape their action; thus, with few exceptions, the viral clones isolated from VC10042 were highly resistant to known bNAbs, especially CD4bs antibodies (Sather et al., 2012). Only one viral clone isolated from VC10042 was susceptible to VRC01, but the majority (8 of 12) were moderately susceptible to NIH-45-46 ${ }^{\mathrm{G} 54 \mathrm{~W}}$ (Sather et al., 2012). In contrast, NIH45-46m2 neutralized all (12 of 12) of the viral clones with up to 10 -fold greater potency relative to NIH45-46 G54W $^{\text {when }}$ evaluated against NIH45-46 ${ }^{\mathrm{G} 54 \mathrm{~W}}$-sensitive clones (Fig. 2).

Structural mechanism for the increased potency of $45-46 \mathrm{~m} 2$ To explore the mechanism underlying the increased breadth of $45-46 \mathrm{~m} 2$, we solved the $2.8 \AA$ crystal structure of the $45-46 \mathrm{~m} 2$
Fab bound to 93 TH057 gp120 (Fig. 3 A and Table S3) and compared it with the structure of NIH45-46 bound to the same gp120 (Diskin et al., 2011). The total buried surface area of the $45-46 \mathrm{~m} 2 / g p 120$ complex $\left(3214 \AA^{2}\right)$ was larger than the buried surface area calculated for NIH45-46/gp120 $\left(2636 \AA^{2}\right)$ or

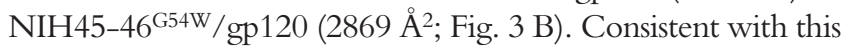
observation, surface plasmon resonance (SPR) binding assays (Fig. 4 A) demonstrated that 45-46m2 Fab exhibited a higher affinity and slower dissociation rate than NIH45-46 $6^{\mathrm{G} 54 \mathrm{~W}} \mathrm{Fab}$ or NIH45-46 Fab for binding 93TH057 gp120 (Fig. 4 B). The increased buried surface area for the 45-46m2-gp120 complex largely resulted from the predicted (Diskin et al., 2011) penetration of $\operatorname{Trp}_{4} 4_{45-46 \mathrm{~m} 2}$ into the Phe $43_{\mathrm{CD} 4}$ pocket of gp120 (Fig. $3 \mathrm{C}$ ). Local rearrangements in the surrounding residues of the gp120 Phe $43_{\mathrm{CD} 4}$ pocket occurred; Gly $473_{\text {gp } 120}$ was shifted by $\sim 4 \AA$ (C $\alpha$-C $\alpha$ distance) toward $\operatorname{Trp} 54_{45-46 \mathrm{~m} 2}$ due to a hydrogen bond between its carbonyl oxygen and the $\varepsilon$-nitrogen of Trp54 $45-46 \mathrm{~m} 2$, and Ile $371_{\mathrm{gp} 120}$ adopted a different rotamer to accommodate Trp54 45-46m2 (Fig. 3 C). The Gly-Trp substitution at position 54 allowed the tryptophan indole side chain to bury an additional $233 \AA^{2}\left(144 \AA^{2}\right.$ on $45-46 \mathrm{~m} 2$ and $89 \AA^{2}$ on gp120) of surface area in the Fab-gp120 complex, representing 

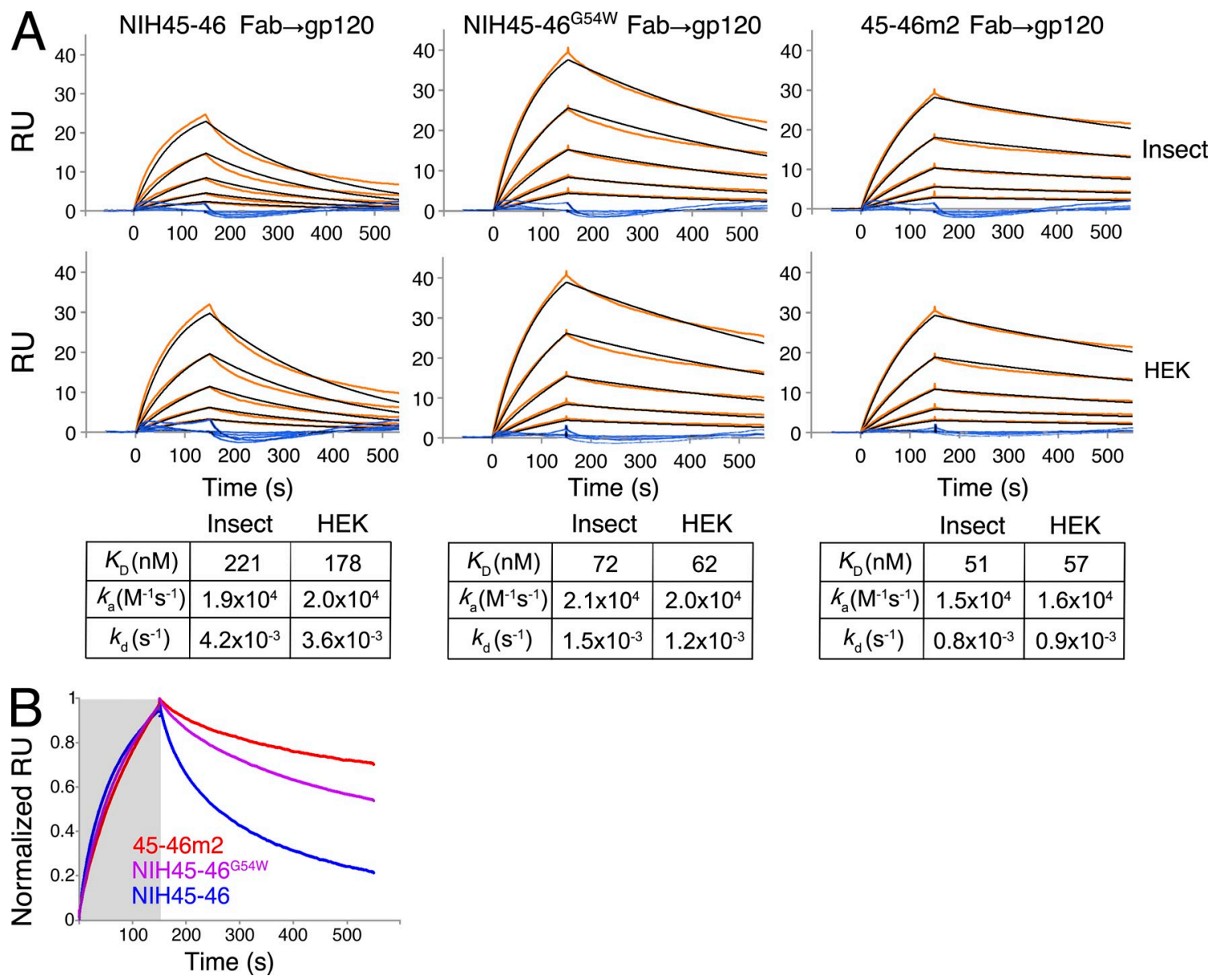

Figure 4. SPR comparisons of the binding of gp120 to NIH45-46, NIH4546 ${ }^{654 \mathrm{~W}}$, and $45-46 \mathrm{~m} 2$ Fabs. (A) Sensograms (orange curves) were recorded for the interactions of injected 93TH057 gp120 produced in insect (Hi5) and mammalian (HEK293) cells over immobilized Fabs derived from the indicated antibodies in a twofold dilution series ranging from 500 to $31 \mathrm{nM}$. Kinetic constants $\left(k_{a}, k_{d}\right)$ were derived from globally fitting the association and dissociation phases using a 1:1 binding model (black curves) and affinities were calculated as $K_{D}=k_{d} / k_{\mathrm{a}}$. Residual plots (blue) within each sensogram describe the fit of the model to the data. Each binding experiment was conducted twice; once using gp120 produced in insect cells and once using gp120 produced in mammalian cells. (B) SPR measurements of 500 nM injected 93TH057 gp120 over the indicated immobilized Fabs. Each curve was normalized to its $R_{\max }$. The gray and white shaded areas designate the association and dissociation phases, respectively.

a favorable energy change of complex formation of approximately $-3.5 \mathrm{kcal} / \mathrm{mol}$ (assuming $-15 \mathrm{cal} / \mathrm{mol} \bullet \AA^{2}$ of buried hydrophobic surface [Vallone et al., 1998]). Although the Fabgp120 protein complex was treated with a deglycosidase before crystallization, some $N$-linked glycans remained intact; thus, we found extended electron density for six monosaccharides of a glycan attached to Asn276 $6_{\text {gp } 120}$ (Fig. 3 D). The 45-46m2 LC made extensive contacts with the Asn $276_{\text {gp } 120}$-attached glycan, and Tyr $28_{45-46 \mathrm{~m} 2(\mathrm{LC})}$ was a central component in this interaction through contacts with the first two $\mathrm{N}$-acetylglucosamines and the subsequent mannose (Fig. 3 E). Arg64 45-46m2(LC), $\operatorname{Trp}_{45-46 \mathrm{~m} 2(\mathrm{LC})}$, and Tyr89 ${ }_{45-46 \mathrm{~m} 2(\mathrm{LC})}$ also contributed to the contact surface with the glycan, which consisted of $554 \AA^{2}$ buried surface area (280 $\AA^{2}$ on $45-46 \mathrm{~m} 2$ and $274 \AA^{2}$ on the glycan). Interactions with the Asn $276_{\mathrm{gp} 120}$-attached glycan by an aromatic residue in position $65_{\mathrm{LC}}$ rationalize the observation that $\operatorname{Trp} 65_{\mathrm{LC}}$ / Phe65 $5_{\mathrm{LC}}$ are characteristic residues selected for during affinity maturation in the LCs of PVL antibodies (West et al., 2012).

\section{Variations from a gp120 consensus sequence confer resistance to NIH45-46 ${ }^{654 W}$}

We next examined the interactions between 45-46m2 and gp120 residues within a gp120 consensus sequence identified as involved in resistance to NIH45-46 ${ }^{\mathrm{G}} 4 \mathrm{~W}$ (West et al., 2012). In most resistant HIV-1 strains, uncommon amino acids replace highly conserved residues in the gp120 D and V5 loops, includ-

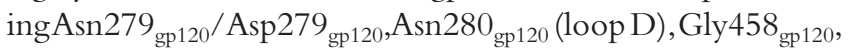
or Gly459 ${ }_{\text {gp120 }}$ (base of loop V5; hereafter referred to as the N/DNGG consensus). The N/DNGG consensus appears in 96.4, 96.3, 96.4, and $93.0 \%$ of 2,869 unique Env sequences from the Los Alamos Database for positions $279_{\mathrm{gp} 120}, 280_{\mathrm{gp} 120}$, $458_{\mathrm{gp} 120}$, and $459_{\mathrm{gp} 120}$, respectively. Furthermore, YU-2 escape mutant viruses isolated from $\mathrm{HIV}-1_{\mathrm{YU}-2}-$ infected mice that were treated with NIH45-46 ${ }^{\mathrm{G} 54 \mathrm{~W}}$ carried mutations within the N/DNGG motif (Klein et al., 2012), selectively mutating the N/DNGG motif in YU-2 pseudoviruses reduced or completely prevented neutralization by NIH45-46 $554 \mathrm{~W}$ (West 

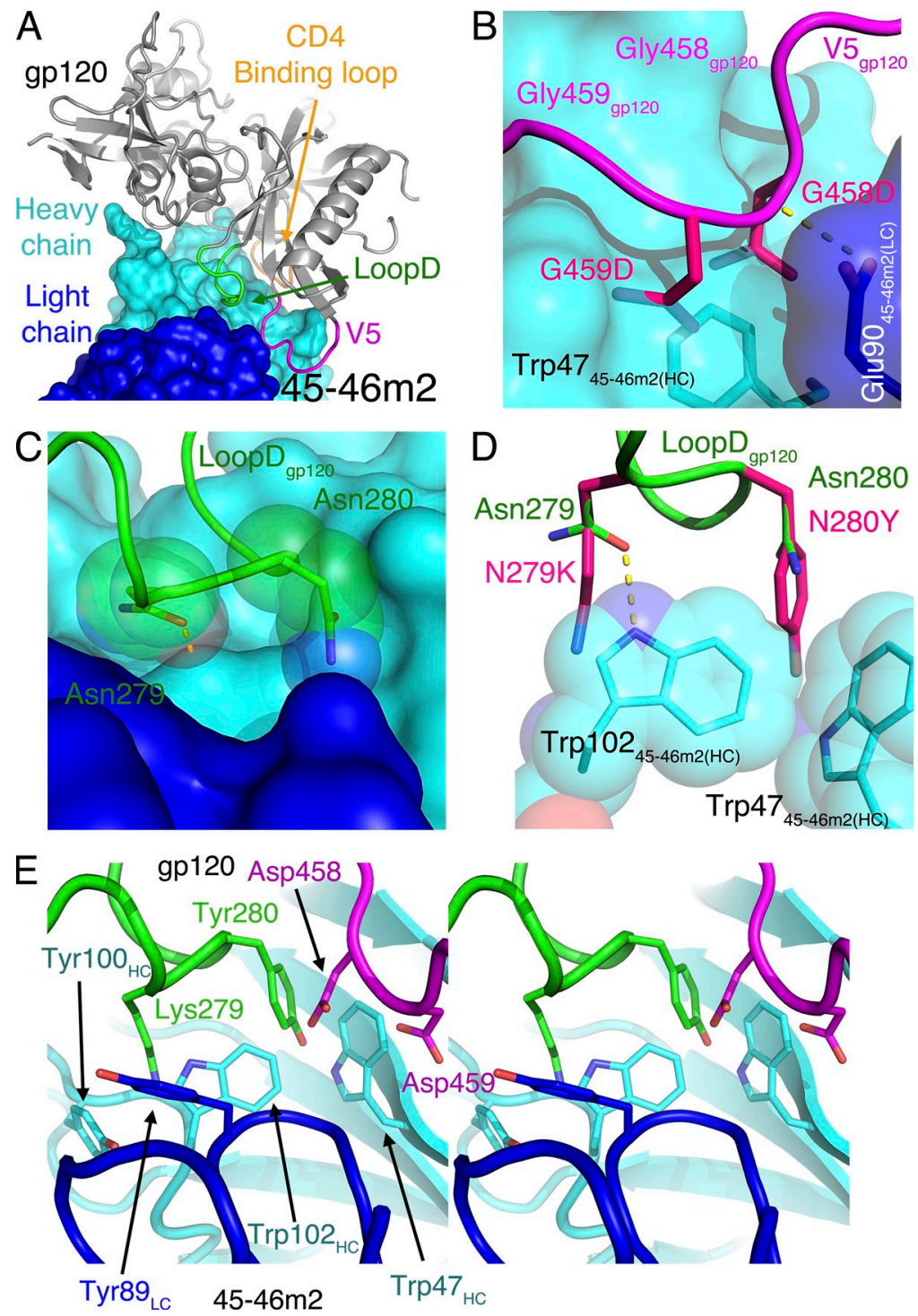

Figure 5. Steric constraints associated with the gp120 N/DNGG motif. (A) Overview of loop D (green) and the $\mathrm{V} 5$ loop (magenta) of gp120 (gray) interacting with the surface of the $45-46 \mathrm{~m} 2 \mathrm{HC}$ (cyan) and LC (blue). The CD4binding loop of gp120 is shown in orange. (B) gp120 V5 loop region showing Gly458 ${ }_{\text {gp } 120}$ and Gly459 ${ }_{\text {gp } 120}$ with overlaid prediction of the consequences of aspartic acid substitutions at these positions (Asp458 $8_{\text {gp } 120}$ and Asp459 gp 120; pink sticks). Both aspartic acids could clash with $\operatorname{Trp}_{45} 7_{45-46 \mathrm{~m} 2(\mathrm{HC}) \text {. }}$ (C) Asn279 gp120 and Asn280 ${ }_{\text {gp } 120}$ (sticks and semitransparent spheres) interactions with $45-46 \mathrm{~m} 2$. A hydrogen bond (orange dashed line) between Asn279 $9_{\mathrm{gp} 120}$ and the nitrogen atom of the $\operatorname{Trp} 102_{45-46 \mathrm{~m} 2(\mathrm{HC})}$ indole ring is shown. (D) Possible steric clashes between a lysine or a tyrosine in gp120 positions 279 and 280 (pink) and $\operatorname{Trp}_{102_{45-46 m 2(H C)}}$ and Trp47 $45-46 \mathrm{~m} 2(\mathrm{HC})$. (E) Stereo image showing modeled substitutions in the gp120 N/DNGG consensus sequence (Lys279 $_{\text {gp 120, }}$ Tyr280 $_{\text {gp 120, }}$ Asp458 gp 120, $_{\text {and }}$ Asp459 gp 120 ) at the interface with $45-46 \mathrm{~m} 2$. Tyr $100_{45-46 \mathrm{~m} 2} \mathrm{HC}$ and Tyr89 $45-46 \mathrm{~m} 2 \mathrm{LC}$ which may impose steric constraints for the binding of gp120s with nonconsensus substitutions, are shown together with $\operatorname{Trp} 102_{45-46 \mathrm{~m} 2 \mathrm{HC}}$ and $\operatorname{Trp} 47_{45-46 \mathrm{~m} 2 \mathrm{HC} \text {. }}$ et al., 2012), and reverting the nonconsensus residues of the resistant T278-50 strain to N/DNGG (A279N/E459G) made it sensitive to NIH45-46 ${ }^{\mathrm{G} 54 W}\left(\mathrm{IC}_{50}=0.07 \mu \mathrm{g} / \mathrm{ml}\right.$; unpublished data).Analysis of the 45-46m2-gp120 complex structure suggests that most changes to the N/DNGG motif (Fig. 5 A) would cause steric constraints for binding of PVL antibodies (Fig. 5, B-D); specifically, substituted residues in the N/DNGG motif are likely to clash with $\operatorname{Trp} 102_{45-46 \mathrm{~m} 2(\mathrm{HC})}$ and $\operatorname{Trp} 47_{45-46 \mathrm{~m} 2(\mathrm{HC})}$ (Fig. 5, B and D), leading to suboptimal or completely abrogated binding. Other residues that may be affected by N/DNGG motif alterations include $\operatorname{Tyr} 100_{45-46 \mathrm{~m} 2(\mathrm{HC})}$ and $\operatorname{Tyr} 89_{45-46 \mathrm{~m} 2(\mathrm{LC})}$ (Fig. 5 E).

To examine the effects of mutations within the N/DNGG motif on neutralization by $45-46 \mathrm{~m} 2$, we used modified YU-2 pseudoviruses each including a substitution in a N/DNGG consensus residue (Fig. $6 \mathrm{~A})$. We also generated a YU-2 strain (YU-2 ${ }^{\mathrm{R} 456 \mathrm{~W}}$ ) with a mutation in Arg456 $6_{\text {gp } 120}$, a highly conserved (95\%) residue mutated in five NIH45-46 ${ }^{\mathrm{G} 54 \mathrm{~W}}$-resistant strains, which is not directly contacted by PVL antibodies but that may influence the conformation of the gp120 V5 loop region (West et al., 2012). With the exception of the Arg456 gp120 mutant, the positions substituted were based upon mutations found in YU-2 escape mutants generated in YU-2-infected humanized mice in response to treatment with NIH45-46 G54W (Klein et al., 2012). Unlike NIH45-46 G54W , which lost activity against most of these mutants (West et al., 2012), 45-46m2 neutralized all to at least some degree and potently neutralized YU-2 $2^{\mathrm{R} 456 \mathrm{~W}}, \mathrm{YU}-2^{\mathrm{G} 458 \mathrm{D}}$, and YU-2 ${ }^{\mathrm{G} 459 \mathrm{D}}$, which partially resisted NIH45-46 ${ }^{\mathrm{G} 54 \mathrm{~W}}$ neutralization (Fig. $6 \mathrm{~A}$ ). Alterations in residues $279_{\mathrm{gp} 120}$ and $280_{\mathrm{gp} 120}$, including an A281T mutation that creates a potential $N$-linked glycosylation site at Asn279 ${ }_{\mathrm{gp} 120}$, were less tolerated by $45-46 \mathrm{~m} 2$ and resulted in significant reductions in neutralization potencies (Fig. $6 \mathrm{~A}$ ). However, the ability of $45-46 \mathrm{~m} 2$ to neutralize mutant YU-2 strains that carried changes in the V5 loop (YU-2 ${ }^{\mathrm{G} 458 \mathrm{D}}$ and YU-2 ${ }^{\mathrm{G} 459 \mathrm{D}}$ ), one of which (YU-2 ${ }^{\mathrm{G} 458 \mathrm{D}}$ ) was only weakly sensitive to neutralization 


\begin{tabular}{|c|c|c|c|c|c|c|c|c|c|c|c|c|c|c|}
\hline Envelope & $\mathbf{4 5 m 1}$ & $\mathbf{4 5 m 2}$ & $\mathbf{4 5 m 4}$ & $\mathbf{4 5 m 5}$ & $\mathbf{4 5 m 6}$ & $\mathbf{4 5 m 7}$ & $\mathbf{4 5 m 8}$ & $\mathbf{4 5 m 9}$ & $\mathbf{4 5 m 1 5}$ & $\mathbf{4 5 m 1 6}$ & $\mathbf{4 5 m 1 7}$ & $\mathbf{4 5 m 1 8}$ & $\mathbf{4 5 m 1 9}$ & $\mathbf{4 5 m 2 0}$ \\
\hline WT & 0.008 & 0.005 & 0.007 & 0.014 & 0.008 & 0.009 & 0.010 & 0.007 & 0.019 & 0.016 & 0.154 & 18.727 & 0.016 & 0.011 \\
\hline N279K & $>50$ & 20.083 & $>50$ & $>50$ & $>50$ & 2.412 & 5.400 & 5.525 & 40.450 & 36.277 & 13.170 & 28.485 & 8.037 & 3.133 \\
\hline N280D & $>50$ & 0.435 & $>50$ & $>50$ & $>50$ & 0.139 & 0.082 & 1.419 & $>50$ & $>50$ & 35.850 & $>50$ & 0.872 & $>50$ \\
\hline N280Y & $>50$ & 2.231 & $>50$ & $>50$ & $>50$ & 0.005 & 0.015 & 0.003 & $>50$ & 0.001 & 16.22 & $>50$ & 9.351 & 7.174 \\
\hline G458D & 28.633 & 0.004 & 47.550 & $>50$ & $>50$ & 0.001 & 0.005 & 0.002 & 26.310 & 5.300 & 2.120 & 2.520 & 0.008 & $>50$ \\
\hline G459D & 0.010 & 0.007 & 1.336 & 0.253 & 0.062 & 0.003 & 0.020 & 0.028 & 0.028 & 2.066 & 0.108 & 6.115 & 0.005 & 0.166 \\
\hline
\end{tabular}

\begin{tabular}{|c|c|c|c|c|c|c|c|c|c|c|c|c|c|c|}
\hline Envelope & 45m21 & $\mathbf{4 5 m 2 2}$ & $\mathbf{4 5 m 2 3}$ & $\mathbf{4 5 m 2 4}$ & $\mathbf{4 5 m 2 5}$ & $\mathbf{4 5 m 2 6}$ & $\mathbf{4 5 m 2 8}$ & $\mathbf{4 5 m 2 9}$ & $\mathbf{4 5 m 3 0}$ & $\mathbf{4 5 m 3 1}$ & $\mathbf{4 5 m 3 2}$ & $\mathbf{4 5 m} \mathbf{3 4}$ & $\mathbf{4 5 m 3 5}$ & $\mathbf{4 5 m 3 6}$ \\
\hline WT & 5.945 & 4.770 & 5.055 & 0.007 & 0.005 & 0.004 & 0.003 & 0.011 & 0.006 & 0.006 & 0.005 & 0.004 & 1.190 & 0.582 \\
\hline N279K & 41.100 & 28.625 & 19.563 & 25.613 & 2.590 & 10.310 & 0.652 & $>50$ & 11.535 & 9.610 & 42.050 & $>50$ & $>50$ & $>50$ \\
\hline N280D & 4.630 & $>50$ & 32.887 & 0.355 & 0.190 & 0.011 & 0.096 & $>50$ & $>50$ & 31.400 & 41.600 & 18.883 & 39.033 & $>50$ \\
\hline N280Y & 5.915 & 39.100 & 6.405 & 0.037 & 0.004 & 0.007 & 0.009 & $>50$ & 9.830 & 8.187 & 15.695 & 0.003 & 9.360 & $>50$ \\
\hline G458D & 2.017 & 5.345 & 2.947 & 0.005 & 0.003 & 0.002 & 0.003 & 28.550 & 2.235 & 0.500 & 2.596 & 0.758 & 2.685 & $>50$ \\
\hline G459D & 0.845 & 0.048 & 0.983 & 0.001 & 0.003 & 0.003 & 0.003 & 0.944 & 0.419 & 0.002 & 0.003 & 0.071 & 3.035 & $>50$ \\
\hline
\end{tabular}

\begin{tabular}{|c|c|c|c|c|c|c|}
\hline $\mathrm{IC}_{50}$ values $(\mu \mathrm{g} / \mathrm{ml})$ & $>50$ & $10-50$ & $1-10$ & $0.1-1$ & $0.01-0.1$ & $<0.01$ \\
\hline
\end{tabular}

Figure 6. Neutralization of YU-2 mutant strains by $45-46 \mathrm{~m}$ antibodies. Mean $I \mathrm{C}_{50}$ values $(\mu \mathrm{g} / \mathrm{ml})$ derived from in vitro neutralization assays for 45-4m antibodies against YU-2 mutants. Three or more independent neutralization assays were performed for each mutant.

by NIH45-46 $\mathrm{G}^{\mathrm{G} 4 \mathrm{~W}}$, indicates that the favorable interaction of $45-46 \mathrm{~m} 2$ with the Asn $276_{\mathrm{gp} 120}$-linked glycan can effectively compensate for the loss of an optimal interaction in the vicinity of $\mathrm{V}_{\mathrm{gp} 120}$ even though the $45-46 \mathrm{~m} 2$ substitution makes no direct contacts to this region. Nonetheless, when evaluated against natural HIV-1 isolates, NIHG45-46 ${ }^{\mathrm{G} 54 \mathrm{~W}}$-resistant strains that carried a nonconsensus N/DNGG motif were also resistant to $45-46 \mathrm{~m} 2$ (Fig. 1 C, blue highlighted strains).

\section{Targeting emerging escape mutants}

To further improve the potency of $45-46 \mathrm{~m} 2$ against escape mutants in general and against nonconsensus N/DNGG motifs in particular, we created 24 antibody mutants designed to reduce steric clashes between $45-46 \mathrm{~m} 2$ and substituted residues in the gp120 N/DNGG motif (Fig. 1 A). The neutralization potencies of the new mutant antibodies were evaluated against the panel of YU-2 mutants (Figs. 6 and 7 A). Modifying critical somatically mutated residues in PVL antibodies $\left(\operatorname{Trp} 102_{45-46 \mathrm{~m} 2(\mathrm{HC})}\right.$, Tyr100 $45-46 \mathrm{~m} 2(\mathrm{HC})$, and Tyr89 $9_{45-46 \mathrm{~m} 2(\mathrm{LC})}$; West et al., 2012) to create mutants $45-46 \mathrm{~m} 4, \mathrm{~m} 5, \mathrm{~m} 6, \mathrm{~m} 16, \mathrm{~m} 17, \mathrm{~m} 18, \mathrm{~m} 20, \mathrm{~m} 21$, $\mathrm{m} 22, \mathrm{~m} 23, \mathrm{~m} 29, \mathrm{~m} 30, \mathrm{~m} 31, \mathrm{~m} 32, \mathrm{~m} 34, \mathrm{~m} 35$, and $\mathrm{m} 36$ did not improve the neutralization profiles of the antibodies (Fig. 6). However, replacing the highly conserved $\operatorname{Trp} 47_{45-46 \mathrm{~m} 2(\mathrm{HC})}$ (a germline residue) with different smaller amino acids resulted in antibodies capable of neutralizing YU-2 $2^{\mathrm{N} 279 \mathrm{~K}}, \mathrm{YU}-2^{\mathrm{N} 280 \mathrm{D}}$, and YU-2 ${ }^{\mathrm{N} 280 \mathrm{Y}}$ (Fig. 7,A and B). These mutants, 45-46m7, 45-46m25, and 45-46m28 (45-46m2 + HC mutations W47V, W47I, and W47T, respectively), effectively neutralized all YU-2 mutants with the exception of YU-2 ${ }^{\mathrm{A} 281 \mathrm{~T}}$, which included a newly introduced potential $\mathrm{N}$-linked glycosylation site at Asn279 gp120.

Fitness cost associated with a glycan at Asn279 gp 120 To explore the effects of the $\mathrm{A} 281 \mathrm{~T}_{\mathrm{gp} 120}$ mutation that $\mathrm{ab}-$ rogated neutralization of the $45-46 \mathrm{~m}$ antibodies, we used a previously described in vitro assay (Sather et al., 2012) to compare the relative fitness of YU-2 mutants that either included (YU-2 $\left.{ }^{\mathrm{A} 281 \mathrm{~T}}\right)$ or did not include (YU-2 WT, YU-2 ${ }^{\mathrm{N} 279 \mathrm{~K}}$, and $\left.\mathrm{YU}-2^{\mathrm{N} 280 \mathrm{D}}\right)$ a potential $N$-linked glycosylation site (Asn279 ${ }_{\text {gp } 120}-X-S e r / T h r 281_{\text {gp } 120}$; Fig. 8 A). Although infectious, YU-2 ${ }^{\mathrm{A} 281 \mathrm{~T}}$ exhibited a disrupted replication profile relative to the other viruses (Fig. $8 \mathrm{~B}$ ), suggesting a fitness cost associated with an Asn279 ${ }_{\mathrm{gp} 120}$-attached glycan. Consistent with this suggestion, only three strains in the Los Alamos Database carry a potential $N$-linked glycosylation site at Asn279 ${ }_{\mathrm{gp} 120}$, all with low predicted glycosylation potentials (Fig. $8 \mathrm{~A}$ and below). In addition, unlike the curves for otherYU-2 variants, the in vitro neutralization curves for YU-2 ${ }^{\text {A281T }}$ saturated at $\sim 50 \%$, suggesting the existence of heterogeneous viral populations resulting from incomplete incorporation of $\mathrm{N}$-linked glycan at Asn279 ${ }_{\text {gp } 120}$ (Fig. 7 B and Fig. 8 C).

Available structural information about CD4 binding to gp120 can be used to rationalize why the viral replication profiles of the YU-2 $2^{\text {A281T }}$ mutant were retarded compared with YU-2WT (Fig. 8 B). The N-linked glycan attached to Asn279 ${ }_{\text {gp } 120}$ that was introduced by the $\mathrm{A} 281 \mathrm{~T}_{\mathrm{gp} 120}$ substitution is predicted to exert a fitness cost for HIV-1 by partially blocking the CD4bs. Indeed if there was not a fitness cost associated with having a glycan at residue 279 , one would not expect the highly correlated amino acid distribution at sites 279 and 281 observed in the Los Alamos database. Specifically, residue $279_{\mathrm{gp} 120}$ is usually Asn (51\%) or Asp (46\%), and this preference is not clade-specific. Residue $281_{\mathrm{gp} 120}$ is Thr in $\sim 11 \%$ ( $n=$ 314 ) of the sequences. However, Thr occurs in only one strain (CH080183_e_p1) that includes Asn at 279 $9_{\mathrm{gp} 120}$, a distribution which has a $<1$ in $10^{100}$ chance of occurring randomly (Fisher Exact test). Furthermore the middle residue of the potential $\mathrm{N}$-linked glycosylation sequence in this strain is proline, which would prevent attachment of an $\mathrm{N}$-glycan to 


\begin{tabular}{|c|c|c|c|c|c|}
\hline \multirow{2}{*}{ A Envelope } & \multicolumn{5}{|c|}{ Antibody } \\
\hline & NIH45-46 ${ }^{\text {G54W }}$ & $45-46 m 2$ & $45-46 \mathrm{~m} 7$ & $45-46 m 25$ & $45-46 m 28$ \\
\hline \multirow{9}{*}{$\begin{array}{l}\text { YU-2 } \\
\text { YU-2 } \\
\text { YU-2 } 279 K \\
\text { YU-2 } \\
\text { YU-2 } \\
\text { YU-2 } \\
\text { YU-280D } \\
\text { YU-2 } \\
\text { Y281T } \\
\text { YU-2 } \\
\text { YU-2 } \\
\text { YU458D } \\
\text { G459D }\end{array}$} & 0.008 & 0.005 & 0.009 & 0.005 & 0.003 \\
\hline & $>50$ & 20 & 2.41 & 2.59 & 0.65 \\
\hline & $>50$ & 0.452 & 0.245 & Not Tested & Not Tested \\
\hline & $>50$ & 0.435 & 0.139 & 0.190 & 0.096 \\
\hline & $>50$ & 2.23 & 0.005 & 0.004 & 0.009 \\
\hline & $\sim 0.1 />50^{*}$ & $\sim 0.1 />50^{*}$ & $\sim 0.1 />50^{*}$ & $\sim 0.1 />50^{*}$ & $\sim 0.1 />50^{*}$ \\
\hline & 5.67 & 0.032 & 0.035 & 0.075 & 0.059 \\
\hline & 28 & 0.004 & 0.001 & 0.002 & 0.003 \\
\hline & 0.01 & 0.007 & 0.003 & 0.003 & 0.003 \\
\hline
\end{tabular}
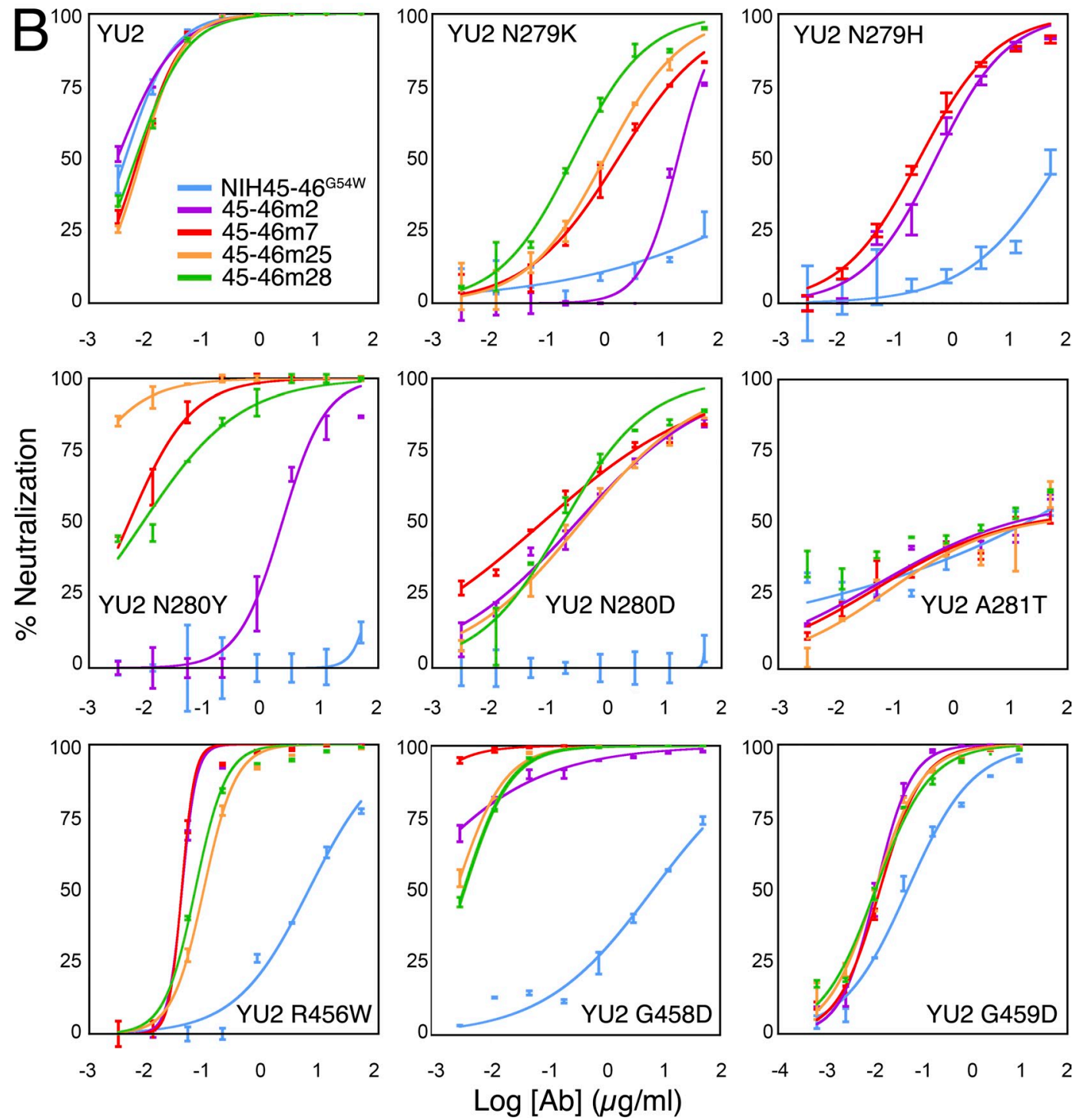

Figure 7. Neutralization of YU-2 mutant strains by selected $45-46 \mathrm{~m}$ antibodies. $(A) I C_{50}$ values $(\mu \mathrm{g} / \mathrm{ml})$ derived from in vitro neutralization assays for selected $45-4 \mathrm{~m}$ antibodies against YU-2 mutant strains. Five independent neutralization assays were performed for each mutant. (B) Neutralization curves for selected YU-2 mutant strains. Error bars represent standard deviation from the mean.

Asn279 $9_{\mathrm{gp} 120}$. Additionally, of the 39 strains with Ser281 ${ }_{\mathrm{gp} 120}$, only three have Asn279 $9_{\mathrm{gp} 120}$ (CY122, 99CMA121, and U14842). An analysis of the glycosylation potential of these three strains
(Fig. $8 \mathrm{~A}$ ) using the NetNGlyc 1.0 Server indicates no glycosylation potential (strains CY122 and U14842) or a very low potential (strain 99CMA121) for Asn279 gp 120 . The YU-2 $2^{\text {A281S }}$ 

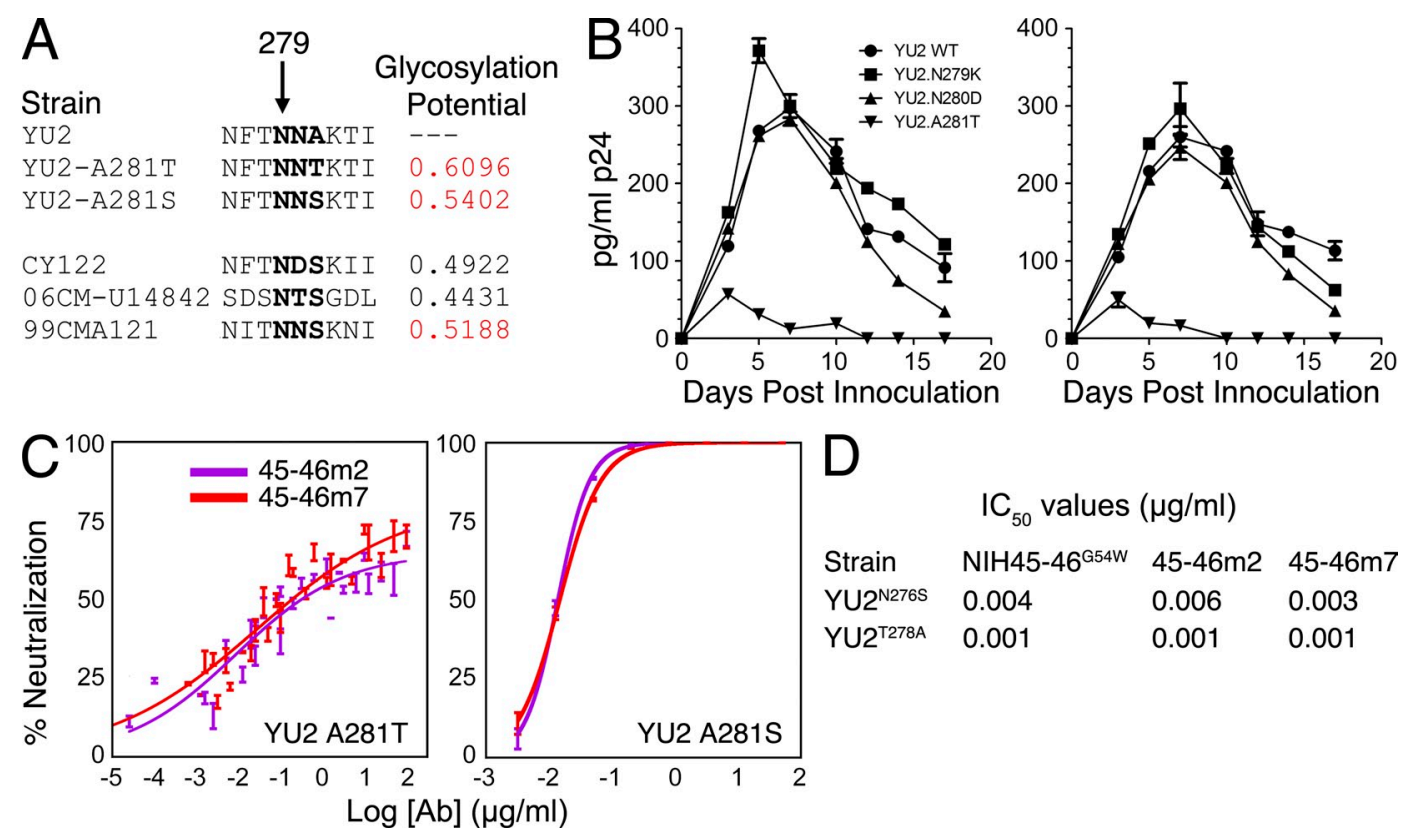

\begin{tabular}{lll}
\multicolumn{1}{l}{$\mathrm{IC}_{50}$ values $(\mu \mathrm{g} / \mathrm{ml})$} & \\
$\mathrm{NIH} 45-46^{\mathrm{G} 54 \mathrm{~W}}$ & $45-46 \mathrm{~m} 2$ & $45-46 \mathrm{~m} 7$ \\
0.004 & 0.006 & 0.003 \\
0.001 & 0.001 & 0.001
\end{tabular}

Figure 8. Analysis of the potential N-linked glycosylation site at Asn279 gp $120^{*}$ (A) Sequence alignment of YU-2, the two YU-2 Ala281 gp120 mutants, and the three known HIV strains with a potential $N$-linked glycosylation site at Asn279 ${ }_{\text {gp 120. }}$. The glycosylation potential for Asn279 ${ }_{\text {gp } 120}$ was calculated for each strain using NetNGlyc 1.0 Server. A glycosylation site is predicted (red highlighted numbers) if the glycosylation potential is $\geq 0.5$. (B) Replication profiles of YU-2 escape mutants. Two independent experiments compared the replication of various YU-2 escape mutants to YU-2 WT in PBMC cell culture. Levels of virus in the supernatant were determined by measuring p24 levels at various time points after inoculation, and each value represents the mean of two replicates each from two independent experiments. (C) Neutralization curves for $45-46 \mathrm{~m} 2$ and $45-46 \mathrm{~m} 7$ against $\mathrm{YU}-2^{A 281 T}$ and $\mathrm{YU}-2^{\mathrm{A} 2815}$. The curves for $\mathrm{YU}-2^{\mathrm{A} 281 T}$ were derived using an extended concentration series. Error bars represent standard deviation from the mean. (D) Neutralization of A281T-associated mutations affecting the Asn276 ${ }_{\mathrm{gp} 120}$-linked glycan.

mutant has a higher glycosylation potential at Asn279 ${ }_{\mathrm{gp} 120}$ compared with the 99CMA121 strain (0.5402 vs. 0.5188; Fig. 8 A), but unlike YU-2 ${ }^{\mathrm{A} 281 \mathrm{~T}}$, the YU-2 $2^{\mathrm{A} 281 \mathrm{~S}}$ mutant was neutralized well (Fig. $8 \mathrm{C}$ ), suggesting that an $N$-glycan was not incorporated at Asn279 ${ }_{\mathrm{gp} 120}$ despite the N-X-S motif.

Considering the close contacts that $45-46 \mathrm{~m} 2$ makes with Asn279gp gp $_{120}$ (Fig. 5 C), an N-linked glycan attached to Asn $279_{\text {gp } 120}$ would most likely prevent $45-46 \mathrm{~m} 2$ binding to gp120s on spike trimers, resulting in resistance to neutralization. The saturation of the YU-2 $2^{\mathrm{A} 281 \mathrm{~T}}$ neutralization curves at values $<100 \%$ (Fig. 7 B and Fig. 8 C) is consistent with both a sensitive and a resistant population of virions, suggesting only partial incorporation of $\mathrm{N}$-linked glycan attached to Asn $279_{\mathrm{gp} 120}$. Incomplete processing at the level of individual gp120 protomers would likely give rise to heterogeneously glycosylated trimeric Env spikes, i.e., trimers that were fully, partially, or not glycosylated at residue 279. At the population level, the sensitivity of YU-2 ${ }^{\mathrm{A} 281 \mathrm{~T}}$ viruses to 45-46m2-like antibodies would vary according to the Env composition of each virus, thereby giving rise to both resistant and sensitive virions within the set of YU-2 $2^{\mathrm{A} 281 \mathrm{~T}}$ viruses.

\section{Combinations of antibodies improve anti-HIV-1 activity in vitro and in vivo}

We next evaluated the breadth and potencies of selected antibodies alone and in combination using the 118 strain crossclade virus panel (Tables S1 and S2). 45-46m7, 45-46m25, and 45-46m28 effectively neutralized YU-2 N/DNGG consensus variants, but these antibodies and a 45-46m2/45-46m7 combination did not neutralize consensus variant strains that were resistant to 45-46m2 (Tables S1, S2, and S4). These results suggest that changing $\operatorname{Trp} 47_{45-46 \mathrm{~m} 2(\mathrm{HC})}$ to a smaller amino acid can only partially alleviate steric constraints associated with PVL antibody binding to an N/DNGG consensus variant. Thus, effective neutralization by $45-46 \mathrm{~m} 7,45-46 \mathrm{~m} 25$, and $45-46 \mathrm{~m} 28$ of escape mutants that use non-N/DNGG consensus residues is likely only when the parent viral strain is sensitive to a PVL antibody. However, given the broad neutralization profiles of parental PVL antibodies (West et al., 2012), strains resistant to parental PVLs and to $45-46 \mathrm{~m} 7$, $45-46 \mathrm{~m} 25$, and $45-46 \mathrm{~m} 28$ as a result of changes in the gp120 N/DNGG consensus sequence are likely to be rare. Addition of 10-1074, a more potent clonal variant of PGT121 (Walker et al., 2011) that recognizes a carbohydrate-dependent epitope associated with the gp120V3 loop (Mouquet et al., 2012), or PG9, a carbohydrate-dependent bNAb recognizing a V1/V2 epitope (Walker et al., 2009), into the mixture resulted in neutralization of almost all resistant strains (Table S4).

Antibodies can drive HIV-1 mutation or even control viral replication in humanized mice (Klein et al., 2012), offering the opportunity to examine HIV-1 escape mutations that arise in response to treatment with selected bNAbs. We compared escape mutations in $\mathrm{HIV}-1_{\mathrm{YU}-2}$ that arose in response to a 45-46m2/45-46m7 combination versus monotherapy with 

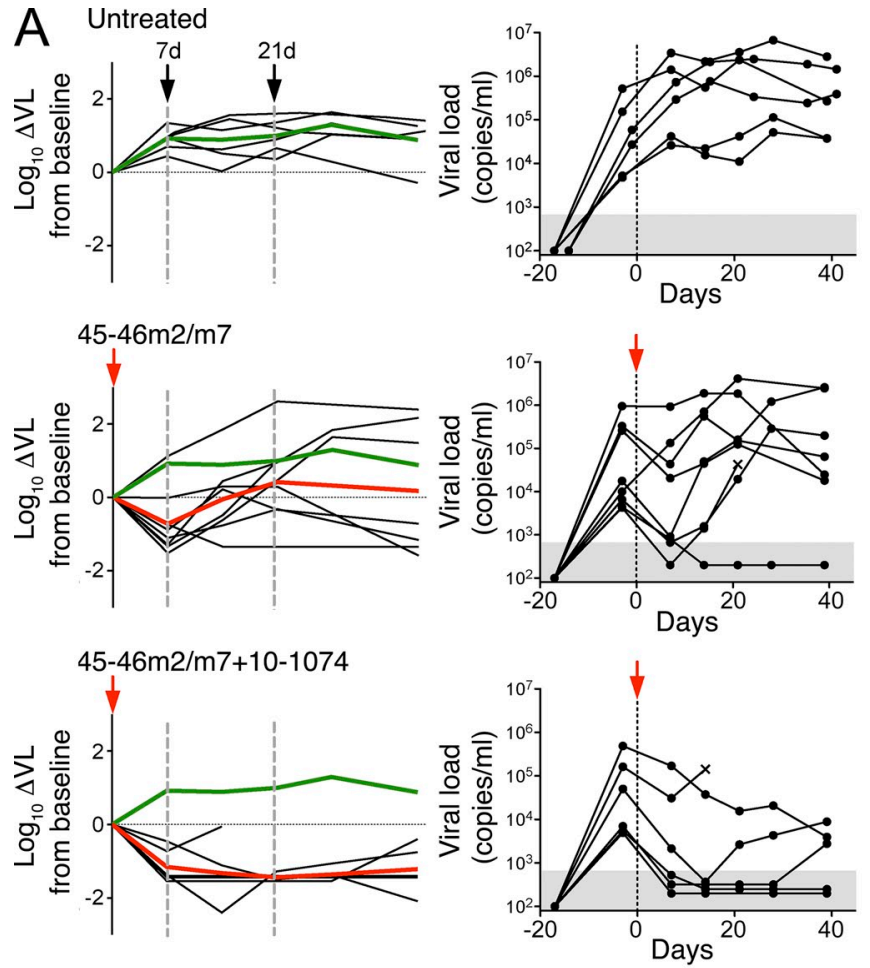

Days post start of treatment
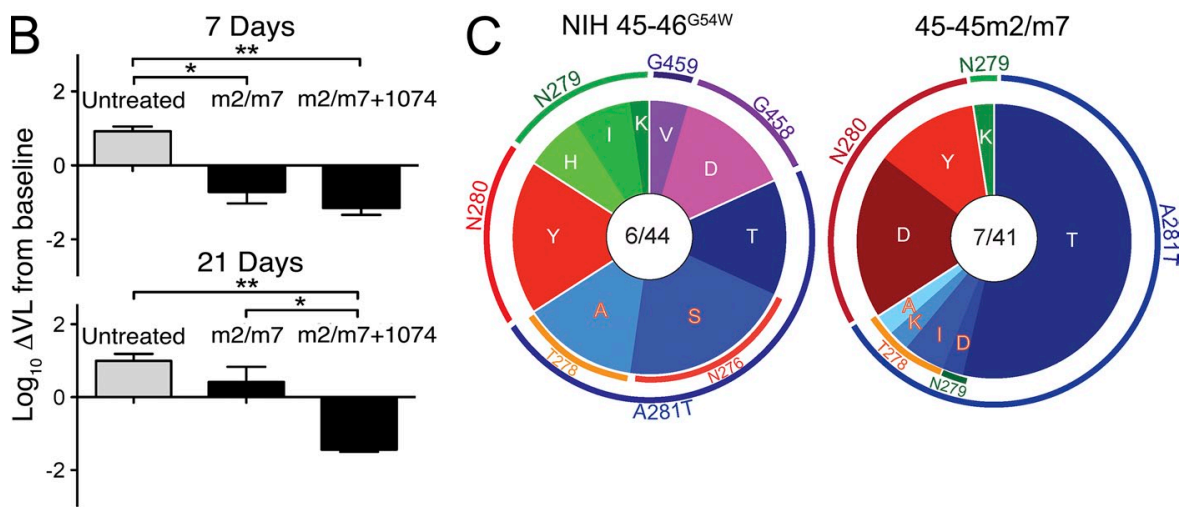

Figure 9. HIV-1 therapy by a combination of two $(45-46 \mathrm{~m} 2+45-46 \mathrm{~m} 7$, labeled $45-46 \mathrm{~m} 2 / \mathrm{m} 7)$ or three $(45-46 \mathrm{~m} 2 / \mathrm{m} 7+$ 10-1074) bNAbs in HIV-1 ${ }_{\text {YU2 }}$-infected humanized mice. (A) Viral load. Left panels: viral load change from baseline $\left(\log _{10}\right.$ HIV-1 RNA copies $/ \mathrm{ml}$ ). Right panels: absolute viral load per mouse (RNA copies/ml). Each line represents a single mouse. Red arrows indicate start of antibody treatment; green lines, geometric mean of untreated mice; red lines, geometric mean of antibody treatment group indicated. Treatment groups were analyzed in parallel and reflect a single experiment comprising six control animals (untreated), eight mice treated with $45-46 \mathrm{~m} 2 / \mathrm{m} 7$, and six animals treated with the combination $45-46 \mathrm{~m} 2 /$ $m 7+10-1074$. Similar results were obtained for the $45-46 \mathrm{~m} 2 / \mathrm{m} 7$ group in an independent experiment involving six mice (not depicted). (B) Mean viral load change $\left(\log _{10}\right.$ HIV-1 RNA copies $/ \mathrm{ml}$ ) from baseline at the indicated number of days from start of therapy (mean and standard error are shown). Statistical test: Kruskal-Wallis test with Dunn's multiple comparison post-hoc test. Asterisks ( ${ }^{*}, \mathrm{P} \leq 0.05$; $\left.{ }^{*}, P \leq 0.01\right)$ reflect statistically significant differences between the treatment groups indicated. (C) Pie charts illustrate the distribution of amino acid changes in gp120 at sites targeted by NIH45-46 $654 \mathrm{~W}$ (left; data from Klein et al., 2012) versus the $45-46(\mathrm{~m} 2 / \mathrm{m} 7)$ combination (right). Wedge sizes reflect the percent of gp120 sequences carrying the indicated resistance mutation at the time of viral rebound. Center numbers refer to the number of mice (left) and the number of gp120 sequences (right) for each set of data. Mutations listed within the A281T sector of the $45-46 \mathrm{~m} 2 / \mathrm{m} 7$ pie chart reflect compensatory mutations accompanying A281T.
NIH45-46 G54W . Treatment with 45-46m2/45-46m7 resulted in a significant initial drop in viremia by $7 \mathrm{~d}$ (Fig. 9, A and B, $\mathrm{P}=0.0057)$. Although viremia rebounded to pretreatment levels after $21 \mathrm{~d}$ in seven of eight mice, the Env sequences isolated from the 45-46m2/45-46m7-treated viremic mice revealed striking differences compared with viruses isolated after escape from NIH45-46 ${ }^{\mathrm{G} 54 \mathrm{~W}}$ monotherapy (Klein et al., 2012; Fig. 9 C, Fig. 10 A, and Table S5 A). Notably, mutations in the GG portion of the N/DNGG consensus sequence $\left({\text { Gly } 458_{\text {gp120 }} \text { and Gly459 }}_{\text {gp 120 }}\right)$, which resulted in resistance to NIH45-46 ${ }^{\mathrm{G} 54 \mathrm{~W}}$ (Fig. $7 \mathrm{~A}$ ) and that were isolated after NIH4546 ${ }^{\mathrm{G} 54 \mathrm{~W}}$ monotherapy (Klein et al., 2012), were absent (Fig. 9 C; Fig. 10 A; Table S5 A). Although effective against potential mutations in the $\mathrm{V} 5$ region (residues $458_{\mathrm{gp} 120}$ and $459_{\mathrm{gp} 120}$ ), the combination of 45-46m2 and 45-46m7 did not eliminate mutations in loop D (residues $279_{\mathrm{gp} 120}$ and $280_{\mathrm{gp} 120}$ ). This may indicate that the antibody concentrations reached in vivo were not sufficient. Consistent with this suggestion, the in vitro $\mathrm{IC}_{50}$ values for 45-46m 2 and 45-46m7 against loop D variants were $>0.1 \mu \mathrm{g} / \mathrm{ml}$ whereas the $\mathrm{IC}_{50}$ values for V5 variants were $<0.01 \mu \mathrm{g} / \mathrm{ml}$ (Fig. $7 \mathrm{~A}$ ).

The predominant escape mutant found in viruses isolated from the 45-46m2/45-46m7-treated mice was A281T $\mathrm{T}_{\mathrm{gp} 120}$, a substitution which introduces a potential $N$-linked glycosylation site at Asn279 ${ }_{\mathrm{gp} 120}$ and results in a less fit virus (Fig. 8 B). In the context of an Asn279 gp120-linked glycan, compensatory mutations to remove the potential $N$-linked glycosylation site at Asn276 $6_{\text {gp } 120}$ were selected (Fig. 9 C, Fig. 10 A, and Table S5 A). Specifically, attachment of an $N$-linked glycan to Asn $276_{\mathrm{gp} 120}$ was prevented by altering the asparagine (N276D and N276S) or the final residue (T278A) in the Asn-X-Ser/ Thr potential $N$-linked glycosylation sequence motif. We speculate that a glycan attached to Asn279 ${ }_{\text {gp120 }}$ in a gp120 lacking Asn276 ${ }_{\mathrm{gp} 120}$-attached glycan could be pushed toward the 


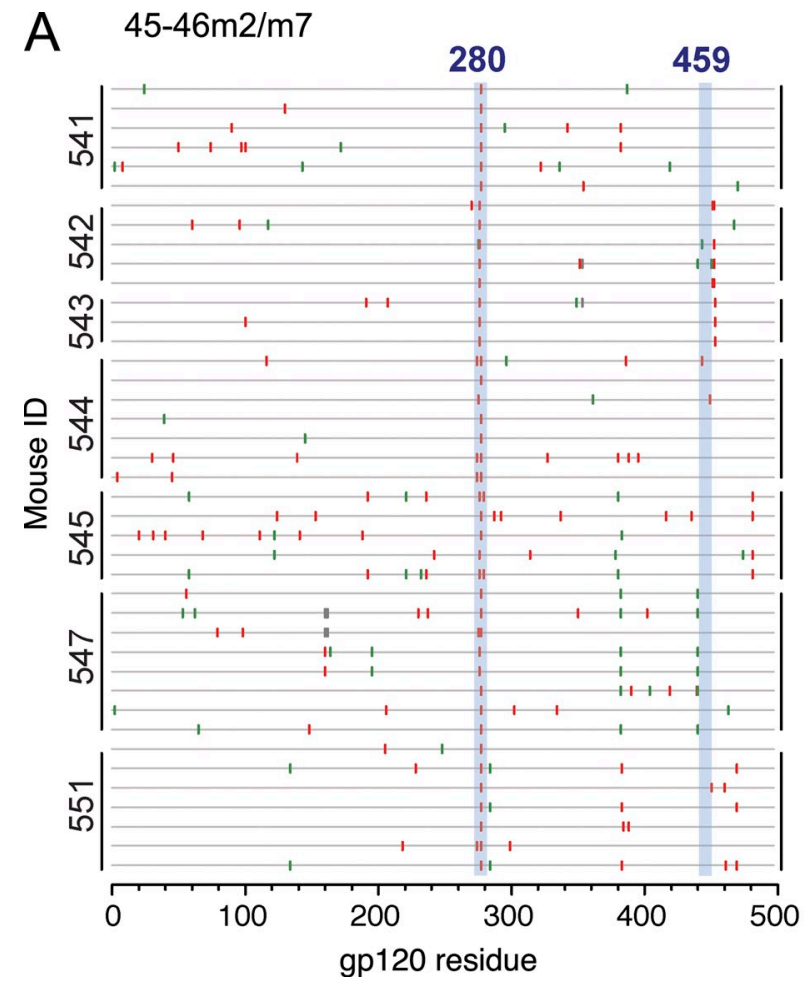

B $45-46 m 2 / m 7+10-1074$

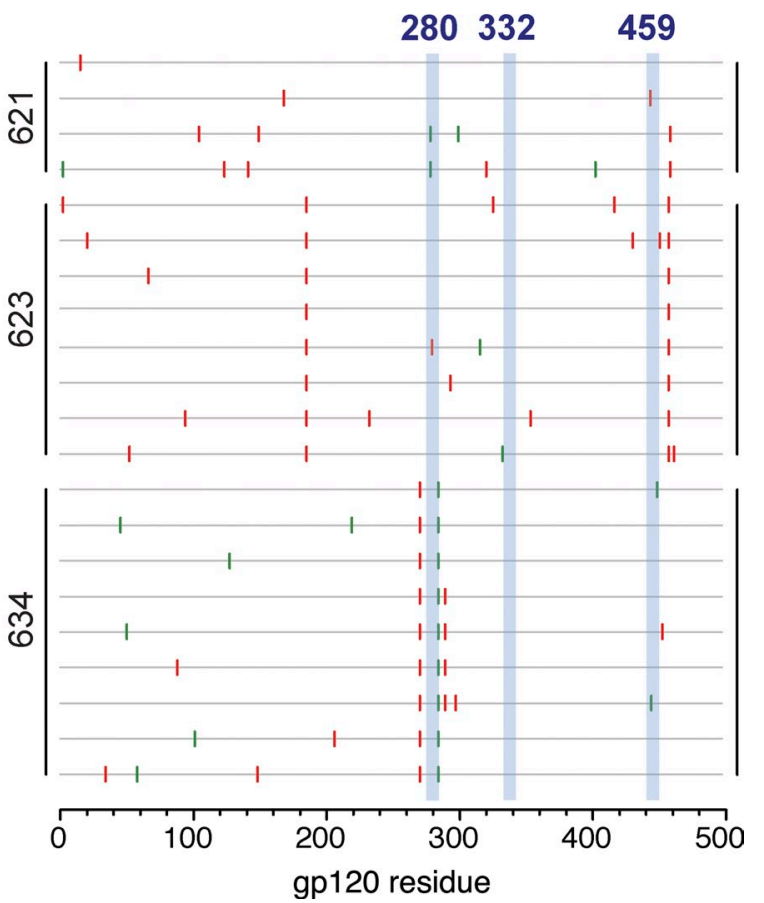

Figure 10. Mutation analysis of gp120 sequences during antibody therapy. HIV-1 YU2 $_{2}$-infected humanized mice were treated with a combination of two $(45-46 \mathrm{~m} 2+45-46 \mathrm{m7}$, labeled $45-46 \mathrm{~m} 2 / \mathrm{m7} ; \mathrm{A})$ or three $(45-46 \mathrm{~m} 2 / \mathrm{m} 7+10-1074 ; \mathrm{B})$ bNAbs and the sequences of gp120s from escape mutant viruses were determined. Individual gp120 nucleotide sequences are represented by horizontal gray bars with silent mutations indicated in green and replacement mutations in red. Shaded vertical lines indicated regions that allowed escape from NIH45-46 ${ }^{654 \mathrm{~W}}$ (amino acid positions 280 and 459 ) and

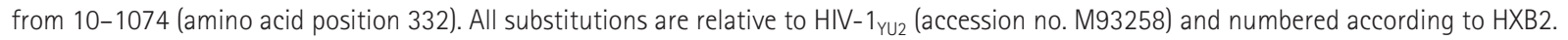

empty space created by elimination of the Asn276 gp120 $_{\text {glycan }}$ to facilitate binding to CD4. Thus, eliminating the glycan at Asn $276_{\mathrm{gp} 120}$ could compensate for the otherwise unfavorable addition of a glycan to Asn279 $9_{\text {gp } 120}$. The suggestion that muta-

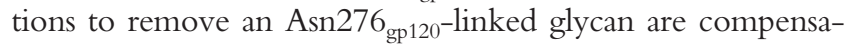
tory mutations required when an Asn279 ${ }_{\text {gp } 120}$-linked glycan is introduced rather than escape mutations on their own is consistent with potent neutralization of N276S and T278A mutants of YU-2 by NIH45-46 ${ }^{\mathrm{G} 54 \mathrm{~W}}, 45-46 \mathrm{~m} 2$, and $45-46 \mathrm{~m} 7$ (Fig. $8 \mathrm{C}$ ) and the emergence of N276S and T278A mutations only when A281T was present (Fig. 10 A and Table S5 A).

When $\mathrm{HIV}-1_{\mathrm{YU} 2}-$ infected mice were treated with a combination of 45-46-m2, 45-46m7, and 10-1074 (Mouquet et al., 2012), we observed control of viremia in all animals that lived beyond $20 \mathrm{~d}$ after the start of treatment (Fig. 9, A and B). With regards to the animal that died before this time, gp120 sequences just before its death did not harbor mutations that would indicate escape from either 10-1074 or $45-46 \mathrm{~m} 2 / \mathrm{m} 7$ (Fig. $10 \mathrm{~B}$ and Table S5 B). Although some mice had detectable viral loads during treatment, we did not find any known escape mutations in viruses isolated during treatment for the bNAbs used in the treatment mix (Fig. $10 \mathrm{~B}$ and Table S5 B). Thus the combination of 45-46m 2 and 45-46m7 effectively reduced the available pathways for escape, and the 45-46m2, 45-46m7, and 10-1074 combination potently treated $\mathrm{HIV}-1_{\mathrm{YU}-2}-$ infected mice.

\section{DISCUSSION}

Antibody-based therapies using combinations of bNAbs are a promising approach for treating or preventing HIV-1 infection (Klein et al., 2012), with the best antibody regimen still to be devised. The successful use of structure-based design to improve NIH45-46 demonstrates that bNAbs, as isolated from HIV-1-infected donors (Scheid et al., 2011), are not necessarily optimal in neutralization breadth or potency. Thus, we were able to create NIH45-46 ${ }^{\mathrm{G} 54 \mathrm{~W}}$, which exhibited an overall 10-fold increased potency over its parental bNAb by changing only a single amino acid (Diskin et al., 2011). Here, we used a combination of structure-based rational design and bioinformatics analyses of sequence features of HIV-1 resistance to construct further improved versions of NIH45-46 $6^{\mathrm{G} 54 \mathrm{~W}}$, resulting in new bNAbs with improved breadth that restrict potential pathways for HIV-1 escape by mutation.

One of the new bNAbs, 45-46m2, neutralizes 96-97\% of HIV-1 strains including VC10042 isolates (Sather et al., 2012) and is equivalent or better on its own than a combination of VRC01 and PG9 (Doria-Rose et al., 2012). Remarkably, 77\% of tested viruses were extremely sensitive to $45-46 \mathrm{~m} 2$, having $\mathrm{IC}_{50}$ values at or below $0.1 \mu \mathrm{g} / \mathrm{ml}$, as compared with $27 \%$ of viruses neutralized by VRC01 at this $\mathrm{IC}_{50}$ cutoff (Fig. $1 \mathrm{~B}$ ). The crystal structure of $45-46 \mathrm{~m} 2$ bound to the clade A/E 93TH057 gp120 revealed that Tyr28 $8_{45-46 \mathrm{~m} 2(\mathrm{LC})}$ makes a favorable 
interaction with the Asn276 $6_{\mathrm{gp} 120}$-attached glycan, rationalizing the observed increase in efficacy compared with NIH45$46^{\mathrm{G} 54 \mathrm{~W}}$. However, although the Asn276 gp120 glycan is highly conserved (a potential N-linked glycosylation site at Asn276 ${ }_{\mathrm{gp} 120}$ is found in $94.7 \%$ of 4279 sequences in the Los Alamos database), it is not required for the formation of infectious particles; thus, virions evolving in the presence of $45-46 \mathrm{~m} 2$ might include mutations that result in the loss of this glycan. Because $45-46 \mathrm{~m} 2$ is not solely dependent on this interaction for neutralization, the loss of the Asn $276_{\mathrm{gp} 120}$ glycan would not necessarily lead to resistance to $45-46 \mathrm{~m} 2$. Indeed, when the Asn276 ${ }_{\mathrm{gp} 120^{-}}$ attached glycan was eliminated from YU-2 gp120, either by mutating the asparagine (N276S) or the threonine (T278A) in the Asn-X-Ser/Thr glycosylation motif, $45-46 \mathrm{~m} 2$ still potently neutralized YU-2 (Fig. 8 D), likely due to other favorable interactions with gp120 of $45-46 \mathrm{~m} 2$ and its parent antibody NIH45-46 ${ }^{\mathrm{G}} 4 \mathrm{~W}$, which lead to potent neutralization of YU-2 by the NIH45-46 ${ }^{\mathrm{G} 54 \mathrm{~W}}$. Strains that were resistant to NIH45$46^{\mathrm{G} 54 \mathrm{~W}}$ but sensitive to $45-46 \mathrm{~m} 2$, such as T250-4 (Tables S1 and S2), are likely to have a higher dependency on the interaction with the Asn276 $6_{\mathrm{gp} 120}$-linked glycan.

Although 45-46m2 showed improved breadth compared with NIH45-46 ${ }^{\mathrm{G} 54 \mathrm{~W}}$ and other bNAbs, it was still unable to neutralize natural HIV-1 isolates that included substitutions in the N/DNGG consensus sequence within the gp120 D and V5 loops. This consensus feature was identified by noticing that uncommon amino acids replaced highly conserved ( $293 \%)$ resi-

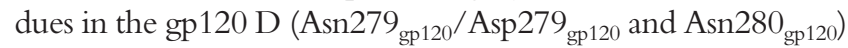
and V5 (Gly458 ${ }_{\mathrm{gp} 120}$ and Gly459 $9_{\mathrm{gp} 120}$ ) loops of most HIV-1 strains that are resistant to NIH45-46 ${ }^{\mathrm{G}} 5 \mathrm{~W}$ (Diskin et al., 2011; West et al., 2012) or arose in YU-2 viruses during in vivo therapy experiments under selective pressure from NIH45-46 $654 \mathrm{~W}$ (Fig. 9 C; Klein et al., 2012). By replacing a highly conserved germline residue, $\operatorname{Trp} 47_{45-46 \mathrm{~m} 2(\mathrm{HC})}$, with different smaller amino acids, we created mutants such as $45-46 \mathrm{~m} 7$ that neutralized YU-2 pseudoviruses with substitutions in the N/DNGG motif more effectively than 45-46m2 (Fig. 7 A). However, both 45$46 \mathrm{~m} 2$ and $45-46 \mathrm{~m} 7$ were ineffective against $\mathrm{YU}-2^{\mathrm{A} 281 \mathrm{~T}}$, a mutant which introduced a potential $N$-linked glycosylation site at Asn279 ${ }_{\text {gp } 120}$. Interestingly, YU-2 $2^{\mathrm{A} 281 \mathrm{~T}}$ exhibited a disrupted replication profile compared with wild-type YU2 and other YU-2 mutants (Fig. 8 B), suggesting a fitness cost associated with an Asn279 ${ }_{\mathrm{gp} 120}$-attached glycan. Decreased fitness of HIV-1 strains with Asn $279_{\mathrm{gp} 120}$-attached glycan is consistent with analyses of gp120 sequences in the Los Alamos database indicating that Asn $279_{\mathrm{gp} 120}$-attached glycan is rare or nonexistent in natural HIV-1 strains. Thus, in vivo treatment with $45-46 \mathrm{~m} 7$ and $45-46 \mathrm{~m} 2$ may drive HIV-1 into a mutation pathway that results in progressively less fit virions.

To assess mutations in HIV-1 that evolve in response to the new bNAbs, we conducted in vivo therapy experiments in HIV-1 ${ }_{\mathrm{YU}-2}-$ infected humanized mice (Fig. 9). Viral escape mutants arising in response to a combination of $45-46 \mathrm{~m} 2$ and $45-46 \mathrm{~m} 7$ were compared with previous results for $\mathrm{HIV}-1_{\mathrm{YU}-2}-$ infected mice treated with NIH45-46 $6^{\mathrm{G}} 4 \mathrm{~W}$ alone (Klein et al., 2012). Env sequences isolated from $45-46 \mathrm{~m} 2 / 45-46 \mathrm{~m} 7$-treated viremic mice did not include mutations in the GG portion of the N/DNGG consensus sequence, whereas viruses including these mutations were isolated after NIH45-46 ${ }^{\mathrm{G} 54 \mathrm{~W}}$ monotherapy (Fig. 9 C, Fig. 10 A, and Table S5 A). Thus, as designed, the new bNAbs successfully restricted the number of pathways that led to escape from their parental bNAb. Indeed, escape from the $45-46 \mathrm{~m} 2 / 45-46 \mathrm{~m} 7$ combination was mostly limited to substitutions involving introduction of a potential $\mathrm{N}$-linked glycosylation site at Asn $279_{\mathrm{gp} 120}$ and substitutions to compensate for the reduced fitness of virions with an Asn279 ${ }_{\text {gp } 120}$-associated glycan (Fig. 9 C). Specifically, the most frequent mutation after 45-46m2/45-46m7 treatment was A281T, a substitution which introduces an Asn279 ${ }_{\mathrm{gp} 120}$-attached N-linked glycan, and compensatory mutations to remove the glycan at Asn276 ${ }_{\mathrm{gp} 120}$ in order to accommodate the otherwise unfavorable addition of carbohydrate at Asn279 $9_{\mathrm{gp} 120}$.

Although we were able to restrict potential pathways for HIV-1 escape from bNAbs, these results illustrate the great difficulty of identifying a bNAb or pair of closely related bNAbs targeting the same epitope that can eliminate all escape pathways. Successful antibody-based therapy strategies may therefore require combinations of bNAbs targeting different epitopes. Previous results demonstrated viremic control in $\mathrm{HIV}-1_{\mathrm{YU}-2^{-}}$ infected humanized mice using a mix of five bNAbs targeting four different epitopes on the viral spike (Klein et al., 2012). Here, we showed that three antibodies, 45-46m2, 45-46m7, and 10-1074 (Mouquet et al., 2012), targeting only two epitopes, can control viremia in vivo (Fig. 9, A and B); thus, this combination of bNAbs was able to suppress both the parental viralYU-2 viral strain and N/DNGG consensus-based escape mutants.

The humanized mice used in these experiments have defective innate and adaptive immunity. For example, they fail to make endogenous antibody responses to HIV (Klein et al., 2012) and T cell responses are difficult to detect (Baenziger et al., 2006; Manz, 2007). Therefore, HIV-1 infections in these mice may be difficult to control in comparison to macaques or humans with an intact immune system. However, humans carry a higher overall viral load, and are susceptible to infection with a diverse group of HIV-1 strains that could make antibody therapy more challenging than the mouse model. Thus, whether or not antibody therapy can be effective in humans remains to be determined. Nevertheless, the addition of $45-46 \mathrm{~m} 2$ and $45-46 \mathrm{~m} 7$ to a mixture of other bNAbs increases the efficacy of antibody-based therapeutics by restricting potential HIV-1 escape pathways and/or selecting mutant virions with reduced fitness.

\section{MATERIALS AND METHODS}

Vector construction, protein expression, and protein purification. Modifications of NIH45-46 HC and LC genes were made using QuikChange Lightning (Agilent Technologies) and verified by DNA sequencing (Eton Bioscience). Antibodies were expressed as IgGs using described protocols (Diskin et al., 2010). In brief, secreted IgGs from polyethyleneimine (25kD, linear; Polysciences)-mediated, transiently transfected HEK293-6E cells were captured on protein A or protein G affinity columns (GE Healthcare) and eluted in $100 \mathrm{mM}$ citrate, $\mathrm{pH}$ 3.0, and $150 \mathrm{mM}$ sodium chloride. Antibodies subsequently used in neutralization assays were dialyzed into $10 \mathrm{mM}$ 
citrate, $\mathrm{pH} 3.0$, and $150 \mathrm{mM}$ sodium chloride and adjusted to a concentration of $1 \mathrm{mg} / \mathrm{ml}$. Fab fragments for crystallization and binding assays were obtained by digesting IgGs in $20 \mathrm{mM}$ Tris, $\mathrm{pH} 8.0$, and $150 \mathrm{mM}$ sodium chloride (TBS) with a 1:100 ratio of papain (Sigma-Aldrich) activated in $50 \mathrm{mM}$ phosphate, $\mathrm{pH}$ 7.0, $2 \mathrm{mM}$ ethylenediaminetetracetic acid, and $10 \mathrm{mM}$ cysteine at $37^{\circ} \mathrm{C}$ until completion of the cleavage (20-60 min, monitored by SDS-PAGE). The Fc was removed by protein A chromatography and Fabs were further purified using Superdex 200 (GE Healthcare) 10/300 Size Exclusion Chromatography (SEC).

The clade A/E 93TH057-derived gp120 core (Zhou et al., 2010; a gp120 construct lacking the V1/V2 and V3 loops) was expressed in insect cells and purified using previously described protocols (Diskin et al., 2011). In brief, supernatants from baculovirus-infected insect cells were collected, buffer exchanged into TBS, and passed through a $\mathrm{Ni}^{2+}$-NTA affinity column (GE Healthcare). gp120 was eluted from the column using TBS plus $250 \mathrm{mM}$ imidazole and purified using Superdex 200 16/60 SEC (GE Healthcare) in TBS supplemented with $0.02 \%$ (wt/vol) sodium azide.

In vitro neutralization assays. We used a previously described pseudovirus neutralization assay (Montefiori, 2005) to assess the neutralization potencies of the various antibodies against multiple HIV-1 strains.YU-2 escape mutant pseudoviruses were generated by cotransfecting HEK293T cells with vectors encoding Env and a replication-deficient HIV-1 backbone as previously described (Montefiori, 2005). Neutralization assays were preformed in-house for evaluating antibody mutants against the YU-2 escape mutants (Table S1 and Fig. 6) and by the Collaboration for AIDS Vaccine Discovery (CAVD) core neutralization facility for testing a subset of the antibodies against a large panel of isolates (Tables S2 and S3). Some of the in-house data were derived from neutralization assays that were dispensed automatically by a Freedom EVO (Tecan) liquid handler $\left(\mathrm{IC}_{50}\right.$ values derived from manual and robotic assays agreed to within two- to fourfold). In all cases, neutralization was monitored by the reduction of a Tat-induced reporter gene (luciferase) in the presence of a three-or fivefold antibody dilution series (each concentration run in duplicate or triplicate) after a single round of pseudovirus infection in TZM-bl cell line (Montefiori, 2005). Antibodies were incubated with 250 viral infectious units at $37^{\circ} \mathrm{C}$ for $1 \mathrm{~h}$ before incubation with the reporter cells $(10,000$ per well) for $48 \mathrm{~h}$. Luciferase levels were measured from a cell lysate using BrightGlo (Promega) and a Victor3 luminometer (PerkinElmer). Data were fit by Prism (GraphPad Software) using nonlinear regression to find the concentration at which $50 \%$ inhibition occurred $\left(\mathrm{IC}_{50}\right.$ value). For evaluating the neutralization of YU-2 escape mutants, at least two independent experiments were performed. Fig. 6 reports mean $\mathrm{IC}_{50}$ values for the various $45-46$ mutants if $0.1<\left(\mathrm{IC}_{50} 1 / \mathrm{IC}_{50} 2\right)<10$. In cases where the two $\mathrm{IC}_{50}$ values did not agree, additional experiments were performed. The reported $\mathrm{IC}_{50}$ values for NIH45-46 $\mathrm{G54 \textrm {W }}, 45-46 \mathrm{~m} 2$, and $45-46 \mathrm{~m} 7$ are means calculated from at least five independent experiments.

Env plasmids for pseudovirus production were provided by B. Hahn (Perelman School of Medicine, University of Pennsylvania Philadelphia, PA), F. McCutchan (The Bill and Melinda Gates Foundation, Seattle, WA), G. Shaw (Perelman School of Medicine, University of Pennsylvania, Philadelphia, PA), D. Montefiori (Duke University Medical Center, Durham, NC), M. Thomson (University of Massachusetts, Amherst, MA), J. Overbaugh (Fred Hutchinson Cancer Research Center, Seattle, WA), R. Swanstrom (University of North Carolina at Chapel Hill, Chapel Hill, NC), L. Morris (Centre for HIV and STIs, National Institute for Communicable Diseases of the National Health Laboratory Services, Johannesburg, South Africa), J. Kim (University College London, London, UK), L. Zhang (School of Medicine, Tsinghua University, Tsinghua, China), D. Ellenberger (Centers for Disease Control and Prevention, Atlanta, GA), and C. Williamson (Institute of Infectious Diseases and Molecular Medicine (IIDMM) and the Division of Medical Virology, University of Cape Town, Cape Town, South Africa).

Crystallization, data collection, model building, and refinement. $45-46 \mathrm{~m} 2$ Fab was purified by Superdex 200 (GE Healthcare) 10/300 SEC in $100 \mathrm{mM}$ citrate, $\mathrm{pH} 3.0,150 \mathrm{mM}$ sodium chloride and combined with an equimolar amount of 93TH057 gp120. After concentration using an Amicon (Millipore) spin column, the complex was incubated with 40,000 units of Endoglycosidase $\mathrm{H}$ (NEB) per $2 \mathrm{mg}$ gp 120 in the absence of detergents at $37^{\circ} \mathrm{C}$ for $16 \mathrm{~h}$ in the manufacturer's recommended buffer. The complex was further purified using Superdex200 (GE Healthcare) SEC in TBS and concentrated to $\mathrm{OD}_{280}=9.5$. Data for the structure determination were collected from rod-like crystals grown in a vapor diffusion sitting drop set at a final volume of $2 \mu \mathrm{l}$ (1:1 protein/reservoir ratio) with $12 \%$ (vol/vol) isopropanol, $10 \%$ (wt/vol) polyethylene glycol 10,000 kD, and $0.1 \mathrm{M}$ citrate, $\mathrm{pH} 5.0$, at $20{ }^{\circ} \mathrm{C}$. The crystals were briefly soaked at $30 \%$ (vol $/ \mathrm{vol}$ ) isopropanol, $5 \%$ glycerol, $10 \%$ (wt/vol) polyethylene glycol 10,000 kD, and $0.1 \mathrm{M}$ citrate, $\mathrm{pH} 5.0$, before flash cooling using liquid nitrogen.

Data to $2.82 \AA$ resolution were collected from a P2 $2_{1} 2_{1} 2_{1} 45-46 \mathrm{~m} 2-$ gp120 complex crystal with similar cell dimensions as the NIH45-46-gp120 crystals (Diskin et al., 2011) at the Stanford Synchrotron Radiation Lightsource (SSRL) beamline 12-2 using a Pilatus 6M (Dectris) detector and $0.9537 \AA$ radiation (Table S5). Data were indexed, integrated, and scaled using XDS (Kabsch, 2010; Table S5). Using Phaser (McCoy et al., 2007) and the NIH4546-gp120 complex (PDB: 3U7Y) as a search model, we found a molecular replacement solution comprising one 45-46m2 Fab and one gp120 in the asymmetric unit. Several rounds of simulated annealing were performed in initial refinement cycles to minimize model bias. The structure was refined using iterative cycles of refinement using the Phenix crystallography package (Adams et al., 2010) and Coot (Emsley et al., 2010) for manual rebuilding. To facilitate refinement at $2.82 \AA$, we restrained the model by using the NIH45-46-gp120 structure as a reference and applying secondary structure restraints. The final model $\left(\mathrm{R}_{\text {free }}=23.1 \%, \mathrm{R}_{\text {work }}=19.3 \%\right)$ consists of 5,998 protein atoms, 242 carbohydrate atoms, and 23 water molecules. 95.63, 4.1, and $0.26 \%$ of the residues are in the favored, allowed, and disallowed regions, respectively, of the Ramachandran plot. The first glutamine of the 45-46m2 HC was modeled as 5-pyrrolidone-2-carboxylic acid. Disordered regions that were not modeled include residues $1-2$ and 210 (the $\mathrm{C}$ terminus) of the 45-46m2 LC, residues 133-136 and 219-221 (the C-terminus) of the 45-46m2 HC, and residues 302-308 (a short linker substituting for the V3 loop), residues 397-408 (a total of 6 residues from V4), and the $6 \mathrm{x}-\mathrm{His}$ tag of 93 TH057 gp120.

Structures were analyzed and figures were prepared using PyMol (Schrödinger). Buried surface areas were was calculated using a $1.4 \AA$ probe using Areaimol as implemented in CCP4i package (Collaborative Computational Project, Number 4, 1994).

SPR measurements. SPR data were collected using a Biacore T200 instrument (GE Healthcare). We used primary amine coupling chemistry to immobilize 1000 resonance units (RU) of the Fabs of NIH45-46, NIH45$46^{\mathrm{G} 54 \mathrm{~W}}$, or $45-46 \mathrm{~m} 2$ in $10 \mathrm{mM}$ acetate, $\mathrm{pH} 5.0$, at a concentration of $0.2 \mu \mathrm{M}$ to a CM5 sensor chip as described in the Biacore manual. Flow channel 1 was mock coupled and served as a blank subtraction channel. gp120 protein was injected as a twofold dilution series $(500-31.2 \mathrm{nM})$ at a flow rate of $80 \mu \mathrm{l} / \mathrm{min}$ at $25^{\circ} \mathrm{C}$ in $20 \mathrm{mM}$ HEPES, $\mathrm{pH} 7.0,150 \mathrm{mM}$ sodium chloride, and $0.005 \%$ (vol $/ \mathrm{vol}) \mathrm{P} 20$ surfactant, and sensor chips were regenerated using $10 \mathrm{mM}$ glycine, $\mathrm{pH} 2.5$. A 1:1 binding model was fit to the blank-subtracted data using the Biacore analysis software to derive kinetic constants $\left(k_{\mathrm{a}}\right.$ and $k_{\mathrm{d}}$; on and off rates) that were subsequently used to calculate affinities ( $K_{\mathrm{D}}$; equilibrium dissociation constant).

In vitro viral fitness assays. Replication experiments were performed as described previously (Neumann et al., 2005; Sather et al., 2012) using wild type YU-2 and three point mutants in gp120 designated as YU-2 ${ }^{\mathrm{N} 279 \mathrm{~K}}$, YU-2 ${ }^{\mathrm{N} 280 \mathrm{D}}$, and YU-2 ${ }^{\mathrm{A} 281 \mathrm{~T}}$. The entire gp160 portion of each $e n v$ variant was inserted into the TN6 replication competent viral backbone, and each construct was transfected into 293T cells to produce infectious virions. Stimulated PBMCs were prepared from whole human blood by Ficoll gradient separation, followed by $72 \mathrm{~h}$ of stimulation by culturing in complete RPMI containing $2 \mu \mathrm{g}$ per $\mathrm{ml} \mathrm{IL}-2$ and $3 \mu \mathrm{g} / \mathrm{ml}$ phytohemagglutinin (PHA). $15 \times$ $10^{6}$ stimulated PBMCs were infected for $3 \mathrm{~h}$ with viral inoculum containing 
the equivalent of $12.5 \mathrm{pg}$ p 24 . After inoculation, the cells were resuspended in fresh complete RPMI/IL-2 media at a density of $3 \times 10^{6}$ cells per ml. At $2-3-d$ intervals, half of the culture supernatant was harvested and replaced with fresh media. Harvested supernatants were assayed for p24 content by capture ELISA (Zeptometrix). During the culture period, the cultures were monitored to ensure that viability remained $>90 \%$.

In vivo therapy experiments. HIV-1 escape experiments were performed in HIV-1 $1_{\mathrm{YU}_{2}}-$ infected humanized mice as previously described (Klein et al., 2012). In brief, nonobese diabetic Rag1 ${ }^{-/-}$IL2R $\gamma^{\text {NULL }}$ (NRG) mice (The Jackson Laboratory) were reconstituted with fetal liver-derived hematopoietic stem cells and infected with HIV-1 $1_{\mathrm{YU} 2}(57.5 \mathrm{ng}$ p24). Mice with viral loads $>4 \times 10^{3}$ copies $/ \mathrm{ml}$ at $14-17 \mathrm{~d}$ after infection were included in treatment experiments. Antibody-treated mice were injected subcutaneously with $1.5 \mathrm{mg} 45-46 \mathrm{~m} 2$ and $1.5 \mathrm{mg} 45-46 \mathrm{~m} 7$ every $2 \mathrm{~d}$, and mice receiving 10-1074 were injected with $0.5 \mathrm{mg}$ antibody twice per week. All experiments were performed with authorization from the Institutional Review Board and the IACUC at the Rockefeller University.

Viral load measurements and sequence analysis of HIV-1 gp120 were performed as previously described (Klein et al., 2012). In brief, total RNA was extracted from $100 \mu$ EDTA-plasma using the QiaAmp MinElute Virus Spin kit as per the manufacturer's protocol. Viral RNA was detected by quantitative reverse-transcriptase PCR using a Stratagene Mx3005P real-time thermal cycler. HIV-specific forward and reverse primer sequences were $5^{\prime}$-GCCTCAATAAAGCTTGCCTTGA- ${ }^{\prime}$ and $5^{\prime}$-GGCGCCACTGCTAGAGATTTT- $3^{\prime}$, respectively. An internal probe $\left(5^{\prime}\right.$-AAGTAGTGTGTGCCCGTCTGTTRTKTGACT-3') contained a 5' 6-carboxyfluorescein reporter and internal/3' ZEN-Iowa Black FQ double-quencher (Integrated DNA Technologies, Inc.). The reaction mix was prepared using the TaqMan RNA-to-Ct 1-Step kit (Applied Biosystems). Cycle threshold values were converted to viral loads using an HIV-1(NL4/3-YU-2) viral preparation of known copy number as a standard.

For gp120 sequencing, viral cDNA was generated from extracted viral RNA (described above) using Superscript III Reverse transcription (Invitrogen) and amplified by gp120-specific nested PCR using the Expand Long Template PCR system (Roche). PCR amplicons were gel purified, cloned into pCR4-TOPO (Invitrogen), transformed into One-Shot TOP10 cells (Invitrogen), and sequenced using the insert-flanking primers M13F and M13R. Sequence reads were assembled using Geneious Pro software version 5.5.6 (Biomatters Ltd) and aligned to HIV-1 ${ }^{\text {YU2 }}$ gp120 (accession no. M93258). Manual edits to sequence assemblies and alignments were performed in $\mathrm{Ge}-$ neious. gp120 residues were numbered according to HXB2, as determined by the Los Alamos Sequence Locator tool (http://www.hiv.lanl.gov/content/ sequence/LOCATE/locate.html).

Online supplemental material. The supplemental material of this paper includes tables of $\mathrm{IC}_{50}$ values for in vitro neutralization assays against a panel of 118 viruses, a table with crystallographic statistics, and a table listing isolated sequences of gp120s recovered from HIV-1 isolated from infected humanized mice after antibody therapy experiments. Online supplemental material is available at http://www.jem.org/cgi/content/full/jem.20130012/DC1.

We thank B. Hahn, F. McCutchan, G. Shaw, D. Montefiori, M. Thomson, J. Overbaugh, R. Swanstrom, L. Morris, J. Kim, L. Zhang, D. Ellenberger, and C. Williamson for contributing the HIV-1 envelope plasmids used in our neutralization panel, Alexander Ploss and Charles M Rice for providing mice for therapy experiments, the Caltech Protein Expression Center, and members of the Bjorkman laboratory for critical reading of the manuscript.

R. Diskin, A.P. West, M.C. Nussenzweig, and P.J. Bjorkman have pending patent applications with the U.S. Patent and Trademark Office, patent numbers U.S. CIT5930-P3 and CIT-6235-P, titled "Improving the Potency and Breadth of Anti-HIV Antibodies-NIH45-46S28Y(LC) with NIH45-46G54W(HC)" and "Overcoming HIV Pathways for Escape using Rationally Designed Anti-HIV Antibodies," respectively. The reagents are available with a Materials Transfer Agreement. R. Diskin is the Tauro Career Development Chair in Biomedical Research. This work was supported by Collaboration for AIDS Vaccine Discovery (CAVD) grants with support from the
Bill and Melinda Gates Foundation (grant 1040753 to P.J. Bjorkman and grant 1032144 to M.S. Seaman); the NIAID of the National Institutes of Health under Award numbers P01Al100148 (P.J. Bjorkman and M.C. Nussenzweig) and UM1Al100663 (M.C. Nussenzweig); NIH grant R01Al081625 (L. Stamatatos)-the content is solely the responsibility of the authors and does not necessarily represent the official views of the $\mathrm{NIH}$; and the Molecular Observatory at Caltech supported by the Gordon and Betty Moore Foundation. Operations at Stanford Synchrotron Radiation Lightsource are supported by the U.S. Department of Energy and NIH. Coordinates and $x$-ray crystallographic data for the $45-46 \mathrm{~m} 2 / \mathrm{gp} 120$ complex have been deposited in the PDB under accession code 4JKP.

The authors declare no competing financial interests.

Author contributions: R. Diskin, M.C. Nussenzweig, and P.J. Bjorkman conceived the study, R. Diskin performed structural determinations, analyses, and design, P.M. Marcovecchio and H. Gao produced and purified proteins, T. Lee, M.S. Seaman, D.N. Sather and L. Stamatatos performed neutralization assays, D.N. Sather and L. Stamatatos performed viral replication analysis, F. Klein, A. Halper-Stromberg, and J.A. Horwitz performed in vivo therapy experiments and analyzed escape mutants, A.P. West helped with data analysis, and R. Diskin and P.J. Bjorkman wrote the paper with contributions from all coauthors.

Submitted: 30 January 2013

Accepted: 1 May 2013

\section{REFERENCES}

Adams, P.D., P.V. Afonine, G. Bunkóczi, V.B. Chen, I.W. Davis, N. Echols, J.J. Headd, L.W. Hung, G.J. Kapral, R.W. Grosse-Kunstleve, et al. 2010. PHENIX: a comprehensive Python-based system for macromolecular structure solution. Acta Crystallogr. D Biol. Crystallogr. 66: 213-221. http://dx.doi.org/10.1107/S0907444909052925

Baba, T.W., V. Liska, R. Hofmann-Lehmann, J. Vlasak, W. Xu, S. Ayehunie, L.A. Cavacini, M.R. Posner, H. Katinger, G. Stiegler, et al. 2000. Human neutralizing monoclonal antibodies of the $\operatorname{IgG} 1$ subtype protect against mucosal simian-human immunodeficiency virus infection. Nat. Med. 6:200-206. http://dx.doi.org/10.1038/72309

Baenziger, S., R. Tussiwand, E. Schlaepfer, L. Mazzucchelli, M. Heikenwalder, M.O. Kurrer, S. Behnke, J. Frey, A. Oxenius, H. Joller, et al. 2006. Disseminated and sustained HIV infection in CD34+ cord blood celltransplanted Rag2-/-gamma c-/- mice. Proc. Natl. Acad. Sci. USA. 103 15951-15956. http://dx.doi.org/10.1073/pnas.0604493103

Balazs, A.B., J. Chen, C.M. Hong, D.S. Rao, L. Yang, and D. Baltimore. 2012. Antibody-based protection against HIV infection by vectored immunoprophylaxis. Nature. 481:81-84. http://dx.doi.org/10.1038/ nature 10660

Collaborative Computational Project, Number 4. 1994. The CCP4 suite: programs for protein crystallography. Acta Crystallogr. D Biol. Crystallogr. 50:760-763. http://dx.doi.org/10.1107/S0907444994003112

Denton, P.W., J.D. Estes, Z. Sun, F.A. Othieno, B.L. Wei, A.K. Wege, D.A. Powell, D. Payne, A.T. Haase, and J.V. Garcia. 2008. Antiretroviral pre-exposure prophylaxis prevents vaginal transmission of HIV-1 in humanized BLT mice. PLoS Med. 5:e16. http://dx.doi.org/10.1371/ journal.pmed.0050016

Diskin, R., P.M. Marcovecchio, and P.J. Bjorkman. 2010. Structure of a clade C HIV-1 gp120 bound to CD4 and CD4-induced antibody reveals anti-CD4 polyreactivity. Nat. Struct. Mol. Biol. 17:608-613. http://dx .doi.org/10.1038/nsmb.1796

Diskin, R., J.F. Scheid, P.M. Marcovecchio, A.P. West Jr., F. Klein, H. Gao, P.N. Gnanapragasam, A. Abadir, M.S. Seaman, M.C. Nussenzweig, and P.J. Bjorkman. 2011. Increasing the potency and breadth of an HIV antibody by using structure-based rational design. Science. 334:1289-1293. http://dx.doi.org/10.1126/science.1213782

Doria-Rose, N.A., M.K. Louder, Z. Yang, S. O’Dell, M. Nason, S.D. Schmidt, K. McKee, M.S. Seaman, R.T. Bailer, and J.R. Mascola. 2012. HIV-1 neutralization coverage is improved by combining monoclonal antibodies that target independent epitopes. J. Virol. 86:33933397. http://dx.doi.org/10.1128/JVI.06745-11

Emsley, P., B. Lohkamp, W.G. Scott, and K. Cowtan. 2010. Features and development of Coot. Acta Crystallogr. D Biol. Crystallogr. 66:486-501. http://dx.doi.org/10.1107/S0907444910007493 
Hessell, A.J., E.G. Rakasz, P. Poignard, L. Hangartner, G. Landucci, D.N. Forthal,W.C. Koff, D.I.Watkins, and D.R. Burton. 2009. Broadly neutralizing human anti-HIV antibody $2 \mathrm{G} 12$ is effective in protection against mucosal SHIV challenge even at low serum neutralizing titers. PLoS Pathog. 5:e1000433. http://dx.doi.org/10.1371/journal.ppat.1000433

Hofman, P., and A.M. Nelson. 2006. The pathology induced by highly active antiretroviral therapy against human immunodeficiency virus: an update. Curr. Med. Chem. 13:3121-3132. http://dx.doi.org/10.2174/ 092986706778742891

Johnson, P.R., B.C. Schnepp, J.C. Zhang, M.J. Connell, S.M. Greene, E. Yuste, R.C. Desrosiers, and K.R. Clark. 2009. Vector-mediated gene transfer engenders long-lived neutralizing activity and protection against SIV infection in monkeys. Nat. Med. 15:901-906. http://dx.doi.org/10 1038/nm.1967

Kabsch, W. 2010. Integration, scaling, space-group assignment and postrefinement. Acta Crystallogr. D Biol. Crystallogr. 66:133-144. http://dx .doi.org/10.1107/S0907444909047374

Keele, B.F., E.E. Giorgi, J.F. Salazar-Gonzalez, J.M. Decker, K.T. Pham, M.G. Salazar, C. Sun, T. Grayson, S. Wang, H. Li, et al. 2008. Identification and characterization of transmitted and early founder virus envelopes in primary HIV-1 infection. Proc. Natl. Acad. Sci. USA. 105: 7552-7557. http://dx.doi.org/10.1073/pnas.0802203105

Klein, F., A. Halper-Stromberg, J.A. Horwitz, H. Gruell, J.F. Scheid, S. Bournazos, H. Mouquet, L.A. Spatz, R. Diskin, A. Abadir, et al. 2012. HIV therapy by a combination of broadly neutralizing antibodies in humanized mice. Nature. 492:118-122. http://dx.doi.org/10.1038/nature11604

Kwong, P.D., R. Wyatt, J. Robinson, R.W. Sweet, J. Sodroski, and W.A. Hendrickson. 1998. Structure of an HIV gp120 envelope glycoprotein in complex with the CD4 receptor and a neutralizing human antibody. Nature. 393:648-659. http://dx.doi.org/10.1038/31405

Louie, M., C. Hogan, M. Di Mascio, A. Hurley, V. Simon, J. Rooney, N. Ruiz, S. Brun, E. Sun, A.S. Perelson, et al. 2003. Determining the relative efficacy of highly active antiretroviral therapy. J. Infect. Dis. 187: 896-900. http://dx.doi.org/10.1086/368164

Manz, M.G. 2007. Human-hemato-lymphoid-system mice: opportunities and challenges. Immunity. 26:537-541. http://dx.doi.org/10.1016/j.immuni .2007 .05 .001

Mascola, J.R., G. Stiegler, T.C. VanCott, H. Katinger, C.B. Carpenter, C.E. Hanson, H. Beary, D. Hayes, S.S. Frankel, D.L. Birx, and M.G. Lewis. 2000. Protection of macaques against vaginal transmission of a pathogenic HIV-1/SIV chimeric virus by passive infusion of neutralizing antibodies. Nat. Med. 6:207-210. http://dx.doi.org/10.1038/72318

McCoy, A.J., R.W. Grosse-Kunstleve, P.D. Adams, M.D. Winn, L.C. Storoni, and R.J. Read. 2007. Phaser crystallographic software. J. Appl. Cryst. 40:658-674. http://dx.doi.org/10.1107/S0021889807021206

Mehandru, S., B. Vcelar, T. Wrin, G. Stiegler, B. Joos, H. Mohri, D. Boden, J. Galovich, K. Tenner-Racz, P. Racz, et al. 2007. Adjunctive passive immunotherapy in human immunodeficiency virus type 1-infected individuals treated with antiviral therapy during acute and early infection. J.Virol. 81:11016-11031. http://dx.doi.org/10.1128/JVI.01340-07

Montefiori, D.C. 2005. Evaluating neutralizing antibodies against HIV, SIV, and SHIV in luciferase reporter gene assays. Curr. Protoc. Immunol. Chapter 12:12: 11

Mouquet, H., L. Scharf, Z. Euler, Y. Liu, C. Eden, J.F. Scheid, A. HalperStromberg, P.N. Gnanapragasam, D.I. Spencer, M.S. Seaman, et al. 2012. Complex-type N-glycan recognition by potent broadly neutralizing HIV antibodies. Proc. Natl. Acad. Sci. USA. 109:E3268-E3277. http://dx.doi.org/10.1073/pnas.1217207109

Nakamura, K.J., C. Cerini, E.R. Sobrera, L. Heath, M. Sinkala, C. Kankasa, D.M. Thea, J.I. Mullins, L. Kuhn, and G.M. Aldrovandi. 2013. Coverage of primary mother-to-child HIV transmission isolates by second-generation broadly neutralizing antibodies. AIDS. 27:337-346. http://dx.doi.org/ 10.1097/QAD.0b013e32835cadd6

Neumann,T., I. Hagmann, S. Lohrengel, M.L.Heil, C.A.Derdeyn, H.G. Kräusslich, and M.T. Dittmar. 2005.T20-insensitive HIV-1 from naive patients exhibits high viral fitness in a novel dual-color competition assay on primary cells. Virology. 333:251-262. http://dx.doi.org/10.1016/j.virol.2004.12.035

Sather, D.N., S. Carbonetti, J. Kehayia, Z. Kraft, I. Mikell, J.F. Scheid, F. Klein, and L. Stamatatos. 2012. Broadly neutralizing antibodies developed by an HIV-positive elite neutralizer exact a replication fitness cost on the contemporaneous virus. J. Virol. 86:12676-12685. http://dx.doi.org/ 10.1128/JVI.01893-12

Scheid, J.F., H. Mouquet, N. Feldhahn, B.D. Walker, F. Pereyra, E. Cutrell, M.S. Seaman, J.R. Mascola, R.T. Wyatt, H. Wardemann, and M.C. Nussenzweig. 2009. A method for identification of HIV gp140 binding memory B cells in human blood. J. Immunol. Methods. 343:65-67. http://dx.doi.org/10.1016/j.jim.2008.11.012

Scheid, J.F., H. Mouquet, B. Ueberheide, R. Diskin, F. Klein, T.Y. Oliveira, J. Pietzsch, D. Fenyo, A. Abadir, K. Velinzon, et al. 2011. Sequence and structural convergence of broad and potent HIV antibodies that mimic CD4 binding. Science. 333:1633-1637. http://dx.doi .org/10.1126/science. 1207227

Trkola, A., H. Kuster, P. Rusert, B. Joos, M. Fischer, C. Leemann, A. Manrique, M. Huber, M. Rehr, A. Oxenius, et al. 2005. Delay of HIV-1 rebound after cessation of antiretroviral therapy through passive transfer of human neutralizing antibodies. Nat. Med. 11:615-622. http://dx.doi.org/10.1038/nm1244

Trkola, A., H. Kuster, P. Rusert, V. von Wyl, C. Leemann, R. Weber, G. Stiegler, H. Katinger, B. Joos, and H.F. Günthard. 2008. In vivo efficacy of human immunodeficiency virus neutralizing antibodies: estimates for protective titers. J. Virol. 82:1591-1599. http://dx.doi.org/10 $.1128 / J V I .01792-07$

Vallone, B., A.E. Miele, P. Vecchini, E. Chiancone, and M. Brunori. 1998. Free energy of burying hydrophobic residues in the interface between protein subunits. Proc. Natl. Acad. Sci. USA. 95:6103-6107. http://dx .doi.org/10.1073/pnas.95.11.6103

Veazey, R.S., R.J. Shattock, M. Pope, J.C. Kirijan, J. Jones, Q. Hu, T. Ketas, P.A. Marx, P.J. Klasse, D.R. Burton, and J.P. Moore. 2003. Prevention of virus transmission to macaque monkeys by a vaginally applied monoclonal antibody to HIV-1 gp120. Nat. Med. 9:343-346. http://dx.doi.org/10.1038/nm833

Walker, L.M., S.K. Phogat, P.Y. Chan-Hui, D. Wagner, P. Phung, J.L. Goss, T. Wrin, M.D. Simek, S. Fling, J.L. Mitcham, et al; Protocol G Principal Investigators. 2009. Broad and potent neutralizing antibodies from an African donor reveal a new HIV-1 vaccine target. Science. 326:285-289. http://dx.doi.org/10.1126/science.1178746

Walker, L.M., M. Huber, K.J. Doores, E. Falkowska, R. Pejchal, J.P. Julien, S.K. Wang,A.Ramos,P.Y.Chan-Hui, M. Moyle, et al; Protocol G Principal Investigators. 2011. Broad neutralization coverage of HIV by multiple highly potent antibodies. Nature. 477:466-470. http://dx.doi.org/10.1038/nature10373

West, A.P. Jr., R. Diskin, M.C. Nussenzweig, and P.J. Bjorkman. 2012. Structural basis for germ-line gene usage of a potent class of antibodies targeting the CD4-binding site of HIV-1 gp120. Proc. Natl. Acad. Sci. USA. 109:E2083-E2090. http://dx.doi.org/10.1073/pnas.1208984109

Wu, X., Z.Y.Yang,Y. Li, C.M. Hogerkorp, W.R. Schief, M.S. Seaman, T. Zhou, S.D. Schmidt, L. Wu, L. Xu, et al. 2010. Rational design of envelope identifies broadly neutralizing human monoclonal antibodies to HIV-1. Science. 329:856-861. http://dx.doi.org/10.1126/science.1187659

Zhou, T., I. Georgiev, X. Wu, Z.Y. Yang, K. Dai, A. Finzi, Y.D. Kwon, J.F. Scheid, W. Shi, L. Xu, et al. 2010. Structural basis for broad and potent neutralization of HIV-1 by antibody VRC01. Science. 329:811-817. http://dx.doi.org/10.1126/science.1192819 